2 Received Date : 29-Jan-2016

3 Revised Date : 01-Jul-2016

4 Accepted Date : 06-Jul-2016

5 Article type : Article

RH: Cohort variation in body size

\title{
Cohort variation in individual body mass dissipates with age in large herbivores
}

1

(3)

4

${ }^{1}$ Department of Arctic and Marine Biology, Faculty of Biosciences, Fisheries and Economics,

17 UiT The Arctic University of Norway, 9037 Troms $\varnothing$, Norway

${ }^{2}$ Université de Lyon, Université Lyon 1; CNRS, UMR 5558 “Biométrie et Biologie Evolutive”,

\section{F-69622, Villeurbanne, France}

$20{ }^{3}$ The James Hutton Institute, Craigiebuckler, Aberdeen, AB15 8QH, UK

$21{ }^{4}$ Département de biologie and Centre d'études Nordiques, Université Laval, Québec, Québec,

22 G1V 0A6, Canada

$23{ }^{5}$ Jonas Ventures, Manhattan, KS, 66502, USA

$24{ }^{6}$ Département de biologie and Centre d'études Nordiques, Université de Sherbrooke, Sherbrooke,

25 Québec, J1K 2R1, Canada

$26 \quad{ }^{7}$ Office National de la Chasse et de la Faune Sauvage, Unité Faune de Montagne, 5 allée de

27 Bethléem, Z.I. Mayencin, 38610, Gières, France

$28{ }^{8}$ Behaviour and Evolution Research Group, School of Natural Sciences, University of Stirling,

29 Stirling EK9 4LA, UK

309 Amboseli Trust for Elephants, P.O. Box 15135, Langata, Nairobi 00509, Kenya

$31{ }^{10}$ Institute of Evolutionary Biology, University of Edinburgh, The Kings Buildings,

32 Ashworth Labs, Charlotte Auerbach Road, Edinburgh EH 3FL, UK

This is the author manuscript accepted for publication and has undergone full peer review but has not been through the copyediting, typesetting, pagination and proofreading process, which may lead to differences between this version and the Version of Record. Please cite this article as doi: 10.1002/ecm.1232

This article is protected by copyright. All rights reserved 
Hamel et al.

33 34

35 * Corresponding author:

36

sandra.hamel@uit.no

${ }^{11}$ Norwegian Institute of Nature Research, Fram Centre, NO-9296 Troms $\varnothing$, Norway
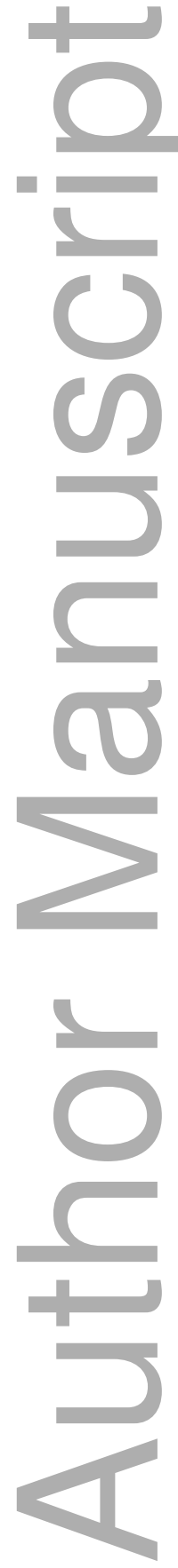

This article is protected by copyright. All rights reserved 


\section{ABSTRACT}

Environmental conditions experienced during early growth and development markedly shape phenotypic traits. Consequently, individuals of the same cohort may show similar life-history tactics throughout life. Conditions experienced later in life, however, could fine-tune these initial differences, either increasing (cumulative effect) or decreasing (compensatory effect) the magnitude of cohort variation with increasing age. Our novel comparative analysis that quantifies cohort variation in individual body size trajectories shows that initial cohort variation dissipates throughout life, and that lifetime patterns change both across species with different paces of life and between sexes. We used longitudinal data on body size (mostly assessed using mass) from 11 populations of large herbivores spread along the "slow-fast" continuum of life histories. We first quantified cohort variation using mixture models to identify clusters of cohorts with similar initial size. We identified clear cohort clusters in all species except the one with the slowest pace of life, revealing that variation in early size is structured among cohorts and highlighting typological differences among cohorts. Growth trajectories differed among cohort clusters, highlighting how early size is a fundamental determinant of lifetime growth patterns. In all species, among-cohort variation in size peaked at the start of life, then quickly decreased with age and stabilized around mid-life. Cohort variation was lower in species with a slower than a faster pace of life, and vanished at prime age in species with the slowest pace of life. After accounting for viability selection, compensatory/catch-up growth in early life explained much of the decrease in cohort variation. Females showed less phenotypic variability and stronger compensatory/catchup growth than males early in life, whereas males showed more progressive changes throughout life. These results confirm that stronger selective pressures for rapid growth make males more vulnerable to poor environmental conditions early in life and less able to recover after a poor start. Our comparative analysis illustrates how variability in growth changes over time in closely related species that span a wide range on the "slowfast" continuum, the main axis of variation in life-history strategies of vertebrates. 
Keywords: Compensatory growth, catch-up growth, cumulative effects, cohort, lifehistory tactics, mixture models, ungulates, sexual selection, "slow-fast" continuum, viability selection.

\section{INTRODUCTION}

At the population level, the expression of life-history traits as individuals age results from a combination of ontogenetic, selective (both viability and fertility selection, Fisher 1930), and environmental processes (Coulson and Tuljapurkar 2008, Ozgul et al. 2009). Because conditions early in life usually determine juvenile body development and size (Madsen and Shine 2000, Metcalfe and Monaghan 2001, Bateson et al. 2004, Solberg et al. 2004), variability in early conditions often leads to phenotypic differences among individuals of a population at the start of life (Lindström 1999). Conceptually, this means that environmental conditions, in interaction with genotype, set the phenotypic starting values of individual life-history traits (Figs. 1a, b). This variability must be considered when assessing changes in a trait with age. If initial differences persist, they result in the ranking of individuals for a given trait that remain constant throughout life (Lindström 1999, Metcalfe and Monaghan 2001, Monaghan 2008). Differences among individuals that are fixed at birth are referred to as fixed or static heterogeneity (Tuljapurkar et al. 2009). In addition to early-life conditions, environmental conditions experienced later in life also influence life-history traits (Wooller et al. 1992, McNamara 1998, Descamps et al. 2008, Wilkin and Sheldon 2009, Crowley and Hopper 2015). The resulting individual differences later in life are referred to as dynamic heterogeneity when they are generated from a stochastic process affecting changes in life-history stages (Tuljapurkar et al. 2009). If individual differences later in life display positive serial auto-correlations, environmental effects may cumulate with age and accentuate between-individual differences over the lifetime, hereafter referred to as "cumulative effect" (Nussey et al. 2007, Dmitriew 2011; Fig. 1d). On the other hand, if individuals can recover from a poor start (Metcalfe and Monaghan 2001, Dmitriew 2011), due to improved conditions and/or genetic predisposition, individual differences will decrease with increasing age, hereafter referred to as "compensatory effect" (Fig. 1c). In bighorn sheep (Ovis canadensis) for instance, lighter yearling females prolonged growth so that their size difference with heavier yearling females decreased from 20 to $4 \%$ between 1 and 7 years of age (Marcil- 
Ferland et al. 2013). Conceptually, cumulative or compensatory effects imply that environmental conditions, along with genotype, not only affect the starting values (Figs. 1a, b), but also the rate of change of life-history traits, thereby increasing or decreasing between-individual variance with age (Figs. 1c, d; Schielzeth and Forstmeier 2009, van de Pol and Wright 2009). Importantly, cumulative or compensatory effects can result from actual differences in ontogeny and/or from viability selection among phenotypes (Fisher 1930, Vaupel et al. 1979). For instance, a reduction in the variance of mass with age can result both from the selective disappearance of lighter individuals (Fig. 1e; Gaillard et al. 2000a, van de Pol and Verhulst 2006, Plard et al. 2015, Théoret-Gosselin et al. 2015) and from changes in the growth patterns of lighter versus heavier individuals. Changes in growth patterns can occur either through compensatory growth (i.e. faster growth of lighter individuals when conditions improve) or catch-up growth (i.e. lighter individuals extending the growth period) (Metcalfe and Monaghan 2003).

The intensity of cumulative or compensatory effects might vary among species in relation to their life-history strategies (Stearns 1976). The long generation time of species with a slow pace of life evolved from a strategy that promotes survival over reproduction (Gaillard and Yoccoz 2003). This resulted in environmental canalization of adult survival, which varies little over time or space, and in a high susceptibility of reproductive traits to spatio-temporal changes in environmental conditions. The opposite pattern occurs in short-lived species, with lower variance in reproductive traits and a more variable adult survival (Gaillard and Yoccoz 2003). Thus, the influence of environmental conditions and selection processes on life-history trait distributions is likely to differ between species with slow and fast life-history strategies (Stearns 1983; see Gaillard et al. 2016 for a recent review). The survival of long-lived species might be buffered against environmental variation because individuals may stop allocating energy to reproduction when facing harsh conditions, whereas individuals of short-lived species will jeopardize survival to reproduce. Although long-lived species should be able to compensate/catch-up for a bad start by restraining reproductive effort, short-lived species should engage in reproduction as early as possible and might thus be less able to compensate/catch-up for a bad start (Gaillard and Yoccoz 2003). Life-history tactics can 
also markedly differ between sexes within species under sexual selection (Clutton-Brock 2007). Males in many species of mammals have evolved a "live fast, die young" strategy (sensu Bonduriansky et al. 2008) that involves strong selection for high growth rate to prevail in intra-sexual competition and increase reproductive performance (e.g. Robinson et al. 2006). Therefore, we expect males of sexually dimorphic and polygynous species to be more susceptible to variation in early-life conditions (Wilkin and Sheldon 2009) and to be less able to compensate/catch-up for a bad start than females (Toïgo et al. 1999).

Individual variation early in life can be shaped by several factors, including genotypic differences, parental effects, or early environment (Bernardo 1996, Lindström 1999, Lindström and Kokko 2002, Solberg et al. 2007, Mousseau and Fox 2008, ThéoretGosselin et al. 2015). Unlike genetic and parental effects, environmental conditions during early growth and development affect all individuals born the same year simultaneously. Environmental variation can thus result in strong cohort effects, particularly in populations with low natal dispersal, and can lead to persistent individual differences throughout life, as often reported in vertebrate populations (e.g. Albon et al. 1987, Clutton-Brock 1988, Madsen and Shine 2000, Steinheim et al. 2002, Hastings et al. 2011, Douhard et al. 2013, Hayward et al. 2013, Herfindal et al. 2015). Cohort variation at the start of life can result from limited resource availability in poor years (Madsen and Shine 2000, Descamps et al. 2008), or from a phenological mismatch between the peak in resources and that in energy demands (Thomas et al. 2001, Suarez et al. 2004, Solberg et al. 2007, Plard et al. 2014a). Nutrient deficiency during development in poor years likely affects growth and developmental processes, leading to body size differences among cohorts born under contrasting environmental conditions (Douhard et al. 2013). Initial conditions can cause a 'silver spoon effect' (Grafen 1988), where lasting benefits of being born during a favorable year lead to positive correlations among performance traits in adulthood (Madsen and Shine 2000, van de Pol et al. 2006, Descamps et al. 2008). Because the influence of ontogenetic, selection, and environmental processes are likely to change with individual states, defined as the physiological and environmental conditions that influence survival and reproduction (McNamara and Houston 1996), cohorts born in favorable and unfavorable years should display different responses to selection and 
environmental processes (Metcalfe and Monaghan 2003, Auer 2010, Douhard et al. 2014, Garratt et al. 2015). Therefore, cohorts sharing similar environmental conditions may show similar life-history tactics throughout lifetime, which might differ from other cohorts and from the average tactic observed at the population level (see Figs. 1c, d, e). They may also show different intensity of cumulative or compensatory effects depending on both the ability of surviving individuals to compensate/catch-up for a poor start (Toïgo et al. 1999, Metcalfe and Monaghan 2003, Auer 2010, Dmitriew 2011, Douhard et al. 2014), and the strength of viability selection (Fisher 1930, Vaupel et al. 1979, Ozgul et al. 2009). Assessing how cohort effects change throughout lifetime is crucial to understand population dynamics because cohort variation can either stabilize or destabilize population dynamics (Lindström and Kokko 2002).

Although the effects of environmental conditions on average population responses have received considerable attention, how environmental changes shape the variability in individual responses both within and among cohorts has received little attention (Metcalfe and Monaghan 2003, Wilson et al. 2009). Most previous studies accounted for cohort variation on life-history strategies by including birth year as a random effect to obtain an unbiased assessment of life-history traits. Specific analyses of cohort variation have shown that it is a key process (Metcalfe and Monaghan 2001) shaping individual differences in trait values at different life stages (Albon et al. 1987, Baron et al. 2010, Le Galliard et al. 2010, Douhard et al. 2013). However, how the magnitude of cohort variation changes along trait trajectories over the lifespan, and whether these patterns vary between sexes and among species with different paces of life remain largely unexplored. Assessing the variance in life-history traits at a given life stage and its change with age requires long-term monitoring of individuals over a period sufficiently long to include enough variation in environmental conditions. Here, we performed a comparative analysis of cohort variation based on long-term studies of different species of large herbivores with up to 40 years of longitudinal data collected on body size for individuals of both sexes. Large herbivores provide a unique opportunity to explore cohort variation because the basic life history and ecology of many species are well understood. The species included in this study vary widely in size (Supplementary 
190 Material Fig. S1) and in position along the "slow-fast" continuum of life histories (Table

191 1). Table 2 presents an overview of the research questions addressed.

192

To quantify cohort variation in body size, we first used mixture models (McLachlan and Peel 2000) to define clusters of cohorts with similar body size early in life. Although between-individual variation is usually quantified from estimates of random effects obtained using mixed models, random effects representing the between-individual variation in mixed models are assumed to be normally distributed. This assumption is often violated when clusters among subjects lead to multimodal distributions (Verbeke and Lesaffre 1996, Stamps et al. 2012). This multimodality can bias the random effect estimates used to quantify between-individual variance in mixed models (Verbeke and Lesaffre 1996, Hamel et al 2016). Mixture models incorporate a categorical latent variable that aggregates subjects into clusters sharing similar traits (McLachlan and Peel 2000). This latent variable captures the multimodal dimension of the variability, and thereby accounts for the between-individual variance that might be present at a higher level, i.e. among clusters. Mixture models are therefore particularly useful to identify how ecological and evolutionary processes change over time within a population because they classify individual trajectories (or traits) into clusters of mean trajectories, instead of a single mean population trajectory (Hamel et al. 2016). These models are widely used in psychology, sociology, and medicine to describe the diversity of trajectories within a population over time, such as psychological development or growth (Jones et al. 2001, Hoeksma and Kelderman 2006). They are also used in capture-recapture studies to account for individual differences in survival within populations (Cubaynes et al. 2012, Ford et al. 2012). Therefore, in the presence or expectation of multimodality, mixture models allow determining whether there is variation in life-history tactics within a population, and when there is, they provide an objective classification of subjects into clusters, each representing a typological tactic within a population. Importantly, cluster classification is not fixed. The classification uncertainty is accounted for when estimating the parameters describing each cluster, thereby providing a more objective quantification of each tactic. 
221 Here, using mixture models allowed determining the best level of clustering between a

222 single cluster (population level) and a separate cluster for each cohort (cohort level), thereby identifying typological differences among cohorts. This is a major advantage in a comparative analysis of studies with different durations because the greater the number of cohorts included, the more environmental variation is likely to be encountered by cohorts. By focusing on the higher level of variation rather than on the specificity of each cohort, mixture models allowed quantifying a standardized variance among cohort clusters controlling for the different number of cohorts monitored among populations (Table 1), and hence providing reliable comparisons among species. After having assessed the presence of cohort clusters with mixture models, we used these cohort clusters to estimate cluster-specific trajectories of body size with age, and evaluated whether the cohort clusters displayed different growth trajectories later in life. Furthermore, we used these growth trajectories to determine whether body size variation among cohort clusters increased (cumulative effect) or decreased (compensatory effect) with increasing age. As we found compensatory effects to be predominant, we accounted for the disappearance of individuals with age to separate the influence of viability selection from that of compensatory/catch-up growth. To contrast results among species and between sexes, we developed standardized estimates to test whether generation time, a reliable measure of the pace of life across mammals (Gaillard et al. 2005), and sex, affected the amount of cohort variation and how this variation changed with age.

\section{METHODS}

\section{Study populations}

We compared body size of individuals in 11 populations of 8 species of large herbivores, intensively monitored from birth to death for 13 - 41 years (Table 1). Using generation time to assess the relative position of a given population on the "slow-fast" continuum (see Gaillard et al. 2005 for a justification and e.g. Jones et al. 2008 or Sæther et al. 2013 for applications), these populations displayed a fivefold variation in the pace of life from about 4 years in mouflon (Ovis gmelini) to about 20 years in African elephant (Loxodonta africana; Table 1). Generation time ( $\mathrm{T}_{\mathrm{b}}$, sensu Leslie 1966) was calculated as the inverse of the sum of the elasticities of the recruitment parameters (i.e. the 
252 elements of the first row of a pre-breeding census Leslie matrix based on female demography and calculated over all available years; Caswell 2001), according to Lebreton (2005). Body size was measured as body mass, with the exception of elephants for which shoulder height was used because individual masses were not recorded. Skeletal measures including shoulder height strongly correlate with body mass in adult elephants ( $\mathrm{r}>0.9$; Laws et al. 1975, Christiansen 2004), and provide a reliable measure of variation in mass in this species. Data were collected on a yearly basis for both sexes, except for the two reindeer (Rangifer tarandus) populations for which only females were sampled. Mass was measured at the same period of the year in each population, and when needed, it was adjusted to a specific date to control for seasonal changes (see e.g. Hamel et al. 2010). For elephants, shoulder height was measured throughout the year. Details on study areas and populations have been published elsewhere (references in Table 1).

To assess cohort variation in body size and its changes with increasing age, the analyses followed 6 steps (Table 2, Fig. 2).

\section{Step 1: Selecting the number of cohort clusters}

For each population, we first ran a mixture model to identify clusters of cohorts based on body size, i.e. using individual initial body size as the response variable. Mixture models classify observations into clusters based on the probability of belonging to a given cluster, where each cluster is defined by a separate set of regression parameters (McLachlan and Peel 2000). For data like body size, which follows a Gaussian distribution $N$ with a cluster-specific mean $\mu_{k}(x)=\beta_{k} x$ (where $\beta_{k}$ is the vector of coefficients for the effects of $x$ specific to each cluster $k$, and $x$ is a vector of predictor variables) and a variance $\sigma_{k}^{2}$, a mixture model with $K$ clusters takes the following form:

$$
h(y \mid x, \psi)=\sum_{k=1}^{K} \pi_{k} N\left(y \mid \mu_{k}(x), \sigma_{k}^{2}\right) \quad \text { eqn. } 1
$$

where $y$ is a vector of individual initial body sizes with a conditional density $h$ depending on $x$ (see below for covariate predictors included for each species) and $\psi$, a vector of all parameters of the mixture distribution, where $\psi=\left(\pi_{1}, \ldots, \pi_{K}, \mu_{1}, \ldots, \mu_{K}, \sigma_{1}^{2}, \ldots, \sigma_{K}^{2}\right)$. The 
prior probabilities $\left(\pi_{1}, \ldots, \pi_{K}\right)$ are the proportions of each cluster $k$ in the mixture; $\sum_{k=1}^{K} \pi_{k}=1, \pi_{k}>0$. We refer to Hamel et al. (2016) for a detailed review of the use of mixture models to separate individuals in clusters that present different life-history tactics within a population.

For each population, we ran a mixture model including only the first body size measurements collected (see "age at first measurement" in Table 1) to represent cohort measurements early in life. In some populations, the first measurements were collected during the first summer of life, referred to as age 0 , whereas in other populations the first measurements were available after the first year of life, referred to as age 1 (Table 1). Therefore, the first body size measurement was collected during or just after the first year of life, which corresponds to the inter-birth interval (IBI=1 year) in species with annual reproduction. For African elephants at Amboseli, however, the IBI is approximately 4.5 years (Moss et al. 2011). To be comparable with the other species, we used measurements between ages 0 and 4.5 to assess differences in body size among cohorts, using a single measure per offspring and "age at first measurement" as a covariate to account for growth between ages 0 and 4.5. This was also necessary because young elephants were measured throughout the year. For each population, the model included measurements of both males and females because we sought to pool cohorts that experienced similar environmental conditions and not to segregate cohorts differently for each sex. We therefore included "sex" as a covariate to account for sexual size dimorphism in the first year of life, except for reindeer for which we only had data on females. In addition, we also included covariates known to influence offspring size in some species when these variables were available. Thus, for Soay sheep (Ovis aries), we included the covariate "twin" (born as a twin vs. as a singleton) because twins are born lighter and have slower early growth than singletons (Robertson et al. 1992, CluttonBrock et al. 1996). For elephants, we included the covariate "primiparity of the mother" (primiparous vs. multiparous) because primiparous mothers produce smaller offspring than multiparous mothers (Lee et al. 2013a). 
311 We used the R package "FlexMix" with the "FLXMRglmfix" driver (Grün and Leisch

312 2008) to run a mixture model on each population. We thus fitted a linear mixture model

313 using "individual body size at first measurement" as the dependent variable and including

314 as a fixed covariate "sex" (all species except reindeer), "twin" (Soay sheep), "primiparity

315 of the mother" (elephants) and "age at first measurement" (elephants). We included

316 "cohort" as the latent clustering variable to segregate cohorts in distinct clusters. For each

317 run, we used a minimum of 5 repetitions with random initializations to avoid reaching a

318 local maximum (Grün and Leisch 2008). We used the "stepFlexmix" function, which fits

319 a model with increasing number of clusters $(K)$ sequentially. We then evaluated the best

$320 K$ based on different selection criteria. Indeed, numerous criteria have been proposed to

321 select $K$ in finite mixture models, but there is no agreement yet on the most appropriate

322 statistical method because different selection criteria sometimes result in different $K$

323 being selected, with some criteria performing better than others in some situations and

324 vice versa (McLachlan and Peel 2000, Aitkin et al. 2009, Everitt et al. 2011, Stahl and

325 Sallis 2012, Melnykov 2013, McLachlan and Rathnayake 2014). Therefore, it has been

326 recommended to consider multiple criteria together with theoretical and practical

327 considerations, because results from a single criterion could be misleading (Everitt et al.

328 2011, Stahl and Sallis 2012; see also Hamel et al. 2016 for a review). Thereby, the Ks

329 selected with different criteria represent plausible alternative typologies in a data set.

330 These alternatives can be compared a posteriori to select the best one according to the

331 research objectives, for example by examining the amount of overlap between clusters to

332 limit cases where some criteria appear to overestimate $K$ (Hamel et al. 2016).

333 Accordingly, we compared four criteria: the bootstrap criterion provided in the package

334 FlexMix (Grün and Leisch 2008) and three of the most commonly used criteria (Everitt et

335 al. 2011, Stahl and Sallis 2012), i.e. the Akaike Information Criterion (AIC - using AICc

336 led to the same results), the Bayesian Information Criterion (BIC), and the bootstrap

337 criterion based on the likelihood ratio test statistic (McLachlan 1987). Each of these four

338 criteria has different merits for selecting K (McLachlan and Peel 2000, Brame et al. 2006,

339 Aitkin et al. 2009, Everitt et al. 2011, Cubaynes et al. 2012; Stahl and Sallis 2012, and

340 see Hamel et al. 2016 for a demonstration). Therefore, for each $K$ selected by a given

341 criterion, we obtained the predictions and $95 \%$ confidence intervals (CI) for each cluster. 
342 We then selected $K$ as the highest plausible number of clusters with no overlap among the $34395 \%$ CI of body size (see Fig. 2). The left panels of Fig. 2 illustrate the plausible $K$ s

344 found for two populations: $K=2,3$ or 4 for bighorn sheep at Ram Mountain, and $K=4$ or 6

345 for Soay sheep at St Kilda. In bighorn sheep, two clusters have overlapping 95\% CI for $346 K=4$, but all clusters are distinct for $K=3$, and so $K=3$ was selected. Similarly, $K=4$ was

347 selected for Soay sheep because the alternative with 6 clusters showed overlap among 348 clusters. We selected $K$ accordingly for all populations. In FlexMix, a cluster needs to 349 include a minimum of $5 \%$ of observations to be identified. The minimum value for a 350 cluster was $8 \%$ in mountain goats. The number of individuals in a cluster only affects the 351 uncertainty around the estimates computed for each cluster, not the mean, and these 352 uncertainties are represented by the $95 \%$ CI in the figures. To evaluate whether the magnitude in the structure of cohort variation at the initial age varied across species along the "slow-fast" continuum, we determined the Pearson correlation coefficient (with its $95 \% \mathrm{CI}$ ) between the number of cohort clusters selected and generation time (on a log-

In this first step, males and females of each population were included in the same mixture model because our aim was first to pool cohorts that experienced similar environmental conditions, to later assess whether the same environmental conditions affected the variance of males and females differently. Separate analyses for each sex could have resulted in a cohort year being included in a different cluster for each sex, so that the variance among clusters would be based on different environmental conditions for each sex and would not be comparable. After the clustering, we modeled growth trajectories separately for males and females. Therefore, each population was described by a certain number of cohort clusters, with each cluster including both males and females born the same years, while the difference in size between sexes was accounted for by using sex as a covariate in the model. In the next 5 steps, we used the cohort classification provided by the clusters of the mixture models in step 1 to determine the growth trajectory specific to each cohort cluster, and this separately for each sex because growth trajectories vary between sexes. Therefore, for each population, cohort years in each cluster were extracted from the mixture model (e.g. cluster $1=1995,1999, \ldots, 2005$; cluster $2=1990$, 
$1998, \ldots, 2010$; etc.). Then, all individuals born in the years included in a cluster were assigned the same cluster number. To analyze the sex-specific growth trajectory of each cohort cluster (Steps 2 to 6), we used the data set including all body size measurements of individuals throughout their lifetime and assigned all measurements for a given individual to its respective cluster number.

\section{Step 2: Assessing growth trajectories of cohort clusters}

First, we evaluated whether cohort clusters differed in lifetime growth trajectories for each population and sex. We analyzed each sex separately to account for potential confounding effects of female reproductive status in capital breeding species (see below), and male reproductive status was not available. Furthermore, because growth markedly differs between sexes in sexually dimorphic species and was modeled with a spline, analyzing sexes together would have required a three-way interaction (age, sex and cluster) that would have been difficult to interpret. Our aim was not to assess whether the interaction between age and cluster differed between sexes, but rather to determine whether interactive effects between age and cluster occurred in each sex. We fitted linear mixed models (LMMs) using the R function "Imer" of the "Ime4" package (Bates et al. 2014), including body size as the dependent variable, and including both year and individual identity as random intercepts to account for annual variation and the repeated measures of individuals with age. For the selection of fixed effects, we sequentially compared a model with only age (i.e. no difference among cohort clusters), a model with additive effects of cluster and age (i.e. a unique growth trajectory for all cohort clusters, but cluster-specific size in early life that remained unchanged throughout lifetime), and a model with an interaction between cohort cluster and age (i.e. cluster-specific growth trajectories). We used likelihood ratio test based on the "anova.merMod" function in lme4 to select the best model, which was appropriate since we compared nested models with the same random effects. Age was fitted with a B-spline (package "splines" in R), using likelihood ratio tests to determine the best polynomial degree of the spline function. We used this method throughout the analyses whenever we included a spline effect of age. Furthermore, we pooled data from older ages so that the oldest age examined always included at least 5 individuals. In addition to age and cohort cluster as fixed effects, we 
404 included all the factors reported or expected to affect body mass and for which we had 405 data in each species. We did not systematically look for effects of these variables when 406 there was no biological reason to do so. We included the covariate "reproductive status" 407 for the LMMs on female mass, to account for the influence of producing an offspring on 408 female annual mass in capital breeders. Female body mass in roe deer (Capreolus 409 capreolus) is not affected by reproduction because they are income breeders (sensu 410 Jönsson 1997) that do not rely on body reserves for gestation and lactation, as previously 411 documented empirically in the two roe deer populations included in this study (Andersen 412 et al. 2000, Plard et al. 2014b). Reproductive status was thus not included in the roe deer 413 models. Furthermore, we could not include reproductive status for Wind Cave bison 414 (Bison bison) and mouflon because the data were not available, and for Svalbard reindeer 415 because reproductive status during the previous summer was uncertain for most females. 416 Finally, we included the covariate "twin" and "primiparity of the mother" as a fixed 417 effect in Soay sheep and elephants, respectively. We evaluated model fit by looking at 418 diagnostic plots of residuals. On two occasions a data point seemed to be an outlier, but 419 analyses with and without these points led to similar results. We also performed a visual 420 assessment of parameter estimations by looking at the shapes of the deviance profiles 421 (Bates et al. 2015). Step 3: Standardizing growth trajectories among cohort clusters

429 We standardized the predictions and 95\% CI found at Step 2 to contrast cluster-specific growth trajectories and evaluate how they differed among populations and sexes. A large

For each sex in each population, we then extracted the expected body size, $\beta_{k a}$, and its 95\% confidence interval (CI) at each age $a$ from LMMs for each cohort cluster $k$ (Step 2 of Fig. 2, Supplementary Material Fig. S1). These predictions (Fig. S1) were then used in the next step to compare growth trajectories among cohort clusters. variation in body size occurred among species, such that a $1 \mathrm{~kg}$ difference in female Soay sheep that average $13 \mathrm{~kg}$ at the end of their first summer corresponds to a much larger size variation than a $1 \mathrm{~kg}$ difference in female bison weighing on average $140 \mathrm{~kg}$ at the same age. Therefore, we scaled the difference among cohort clusters in a given sex of a 
435 given population as the relative difference from the mean population value $m$ at each age

436 a. For each sex in each population, we used a LMM including measurements from all

437 cohort clusters but excluding the cluster effect from the model, and then extracted for

438 each age the arithmetic mean prediction, $\beta_{\text {ma }}$, and its $95 \% \mathrm{CI}$. We then computed the

439 relative difference at each age as $\left(\beta_{k a}-\beta_{m a}\right) / \beta_{m a}$, such that a cohort cluster had a value of 0

440 if it did not differ from the mean, and had either a positive or negative value if it was

441 higher or lower than the mean (see Step 3 in Fig. 2). These values were relative to the

442 mean body size of a specific sex in a given population (referred to as "relative

443 difference", see Table 2) and could thus be compared among species and between sexes.

444 Performing all analyses based on scaled absolute differences instead of relative

445 differences led to similar results.

\section{Step 4: Quantifying the magnitude of cohort variation}

To evaluate how the magnitude of cohort variation changed with age, we used the relative differences obtained from Step 3 and calculated the range among all cohort clusters at each age, i.e. the difference between the maximum and the minimum value, hereafter called "range of relative differences" (see Step 4 in Fig. 2, Table 2). We did this using all age-specific size data from the age at first measurement up to the last age when all clusters were measured (black dots in Step 4 of Fig. 2). When at least one cohort cluster was missing at a given age, all data from this age onwards were excluded from analyses (grey dots in Step 4 of Fig. 2). We then evaluated whether the range of relative differences varied between sexes and along the "slow-fast" continuum using a linear model (LM) with a spline effect of age, sex as a factor, a linear effect of generation time, and two-way interactions between age and sex and between age and generation time (using the product for the latter). The data have a hierarchical structure, with population nested in species, and sex crossed with population. However, accounting for this structure using a nested random intercept of population within species did not capture more variability (random effect variance of population within species estimated close to zero), reflecting that populations within species were not strongly dependent, and that variation among populations associated with generation time accounted for much of the variability. We log-transformed the range of relative differences to normalize the residuals, adding 
0.1 because some relative differences were null. We also standardized age to account for differences in the length of the time series between sexes and among species generated by differences in lifespan. Because there was only a single cohort cluster in elephants, we replicated the analysis by including and then excluding this population. Although the influence of generation time was slightly more pronounced when elephants were included, the results were overall similar. We therefore only report the conservative results from analyses excluding elephants. In addition, the range of relative differences was influenced by the number of clusters and the age at first measurement, but including or excluding these covariates in the analysis led to qualitatively similar results.

Step 5: Quantifying cohort variation between each pair of cohort clusters In Step 4, we computed the range in relative differences among all cohort clusters for a given sex and population. In the fifth step, we calculated the difference in relative differences between each pair of cohort clusters, referred to as "paired relative differences" (see Step 5 in Fig. 2, Table 2). This paired analysis better captured the patterns of changes in cohort variation over age within a sex in a given population, illustrating whether different patterns occurred among pairs of cohorts (e.g. differences between cohort clusters 1 and 2 might compensate with age, whereas those between cohort clusters 1 and 3 might cumulate with age). Again, we used all age-specific size measurements from the age at first measurement up to the last age when all clusters were measured (solid lines in Step 5 of Fig. 2).

\section{Step 6: Measuring cumulative vs. compensatory effects}

To determine whether relative cohort variation in size remained constant throughout life, increased (size divergence), or decreased (size compensation), we computed the relative change in paired relative differences between cohort clusters from age $x$ to age $x+1$ (hereafter referred to as "relative change from age to age", Table 2), using the paired relative differences calculated at Step 5 (illustrated in Fig. 4 with their 95\% CI). A positive value indicated an increase in the difference between a pair of cohort clusters with age, and therefore cumulative effects with age. On the other hand, a negative value indicated reduced differences between pairs of cohort clusters with age, and thus 
compensatory effects. A value of 0 indicated no change in cohort variation in size with age between a pair of cohort clusters. We then evaluated whether the relative change from age to age varied between sexes and along the "slow-fast" continuum using a LMM including a spline effect of age, sex as a factor, a linear effect of generation time, and two two-way interactions between age and sex and between age and generation time (using the product for the latter). We included population as a random intercept because we had repeated values. Repetitions were more numerous for populations with more cohort clusters because these populations included a greater number of paired clusters (Fig. 6). Again, adding a nested random intercept of population within species did not capture more variability (random effect variance of population within species estimated close to zero). According to the profile log-likelihood for the parameter of the Box-Cox transformation (package "MASS" in R, Venables and Ripley 2002), we transformed the relative change from age to age to the power 7.5 to normalize the residuals, adding 0.5 to shift the distribution above zero (Supplementary Material Fig. S2). As in Step 4, we standardized age to account for differences in the length of the time series between sexes and among species, due to differences in lifespan. We also repeated this analysis with elephants included and excluded. Again, results were similar but with a more pronounced influence of generation time when elephants, the species with the longest generation time, were included. We only report the conservative results from analyses excluding elephants. Also, including or excluding age at first measurement as a covariate in the analysis led to qualitatively similar results.

\section{Separating compensatory/catch-up growth from viability selection}

We sought to remove the influence of viability selection from that of differences in growth to assess the specific influence of compensatory/catch-up growth on patterns of cohort variation with age. We did this by rerunning Steps 2 to 6 while accounting for the disappearance of individuals (mostly through mortality because emigration was limited or absent in most populations), thereby modeling differences among cohort clusters due only to differences in growth. First, we added the age at last measurement of each individual as a covariate in each LMM run to estimate the growth of a cohort cluster (Step 2). We fitted a LMM according to equation 1 in van de Pol and Verhulst (2006), 
using the age at last measurement to reflect the timing of disappearance (i.e. parameter $\alpha_{i}$ in van de Pol and Verhulst (2006)' s equation). We tested for both a linear and a quadratic effect of age at last measurement and retained the best model based on a likelihood ratio test. Then, we extracted the predicted trajectories of expected body size with age $\left(\beta_{k a}\right)$ from these LMMs that included age at last measurement. As these LMMs provided a measure of within-cohort cluster change in body size that was independent of viability selection (i.e. parameter $\beta_{w}$ in van de Pol and Verhulst (2006)'s equation), we will refer to these parameters as $\beta W_{k a}$, for "within change in $\beta_{k a}$ ". The influence of age at last measurement could differ among cohort clusters of a given sex and population because each cluster was modeled using a different LMM. To obtain the $\beta W_{k a}$ predictions, however, we used the same age at last measurement for all cohort clusters of the same sex and population, using the mean age at disappearance for that sex and population, thereby controlling for the variation in age at disappearance among cohort clusters. Using these growth trajectories adjusted for disappearance, we then computed the standardized growth trajectory for each cohort cluster (Step 3). As the standardized growth trajectories in Step 3 provided a measure of relative difference among cohort clusters calculated as $\left(\beta_{k a}-\beta_{m a}\right) / \beta_{m a}$, we used $\left(\beta W_{k a}-\beta W_{m a}\right) / \beta W_{m a}$, where $\beta W_{m a}$ was obtained from a LMM similar as that for $\beta_{m a}$ in Step 3, but again including age at last measurement as a covariate, with either a linear or quadratic effect. We extracted $\beta W_{m a}$ predictions for the mean age at disappearance for each sex and population. Therefore, the relative difference calculated accounted for the selective disappearance of individuals and allowed us to calculate the relative change from age to age in cohort variation (Step 6) that was only due to differences in growth. Next, we evaluated whether sex and generation time affected the relative change from age to age that was only due to differences in growth. We did this similarly to Step 6, except that we replaced the response variable "relative change from age to age due to both viability selection and growth" with the "relative change from age to age due only to differences in growth". We could then compare the results for the relative change from age to age that represented both viability selection and compensatory/catch-up growth with those only due to differences in growth. Finally, to evaluate the importance of viability selection, we used likelihood ratio tests to determine whether the LMM including age at last measurement as a covariate received 
greater support than the same model without this covariate (i.e. LMMs in Step 2 with and without age at last measurement). We did this separately for each cohort cluster of a given sex in a given population. Note that for the bison population at Konza, disappearance was mostly the result of culling.

\section{RESULTS}

Structure in body size variation among cohorts: number of cohort clusters

We found statistical evidence for distinct cohort clusters in almost all populations, with up to 5 clusters in the Wind Cave bison population (Table 1). Only the Amboseli elephants, the species with the longest generation time, did not exhibit detectable cohort variation in size. In the species with the second longest generation time, the mountain goat (Oreamnos americanus), we found 2 cohort clusters, but one cluster only included two of 25 cohorts, suggesting no structure or low cohort variation in this species. The trend for the number of clusters to decrease with generation time (Table 1) was not statistically significant $(r[95 \% \mathrm{CI}]=-0.33[-0.78,0.33], \mathrm{p}=0.3)$. The data on bison at Konza were characterized by four cohort clusters, but one cluster only included recent cohorts, and thus we could not examine growth trajectories in this cohort cluster because no individual was monitored past age 4 . For bison at Wind Cave, one of the five clusters also had no individual monitored past age 4 . Thus, for the bison populations, we performed steps 2 to 6 , which assess growth trajectories, only for clusters with enough data later in life, i.e. three for Konza and four for Wind Cave.

\section{Growth trajectories of cohort clusters}

Models including an interactive effect between age and cluster received most support in almost all cases (likelihood ratio p's < 0.1, Supplementary Material Table S1), supporting that growth trajectories differed substantially among cohort clusters throughout life. The only exceptions were for roe deer males at Trois Fontaines and female mountain goats where the additive model was retained, and for male mountain goats where the selected model only included age (Supplementary Material Table S1).

\section{Magnitude of cohort variation in body size}


590 The standardized growth trajectories quantifying the relative difference in size (Step 3;

591 Fig. 3) illustrate that variation in size among cohort clusters was generally higher early in

592 life, with an average difference of $20 \%$ and up to $40 \%$ (Fig. 4). This early variation

593 decreased rapidly in the first few years and then stabilized (Fig. 3). The range of relative

594 differences in size among cohort clusters (Step 4; Fig. 4) was influenced by an interactive

595 effect between age and sex, and by an additive effect of generation time (Table 3a).

596 Differences among cohort clusters decreased markedly with increasing age, in both sexes

597 and for any generation time (Fig. 5). Males, however, showed about 7\% greater cohort

598 variation in early life than females, while both sexes displayed similar magnitude of

599 cohort variation in size at the end of life. The decrease in the magnitude of cohort

600 variation in size with increasing age was more progressive and extended for a greater part

601 of life in males than in females, for which cohort variation stabilized just before mid-life

602 (Fig. 5). The strength of the decrease in cohort variation with increasing age was

603 independent of generation time (Table 3a). Nevertheless, populations with a short

604 generation time exhibited more cohort variation in size throughout their entire life than

605 populations with a long generation time (Fig. 5).

606

607

608

Change in the magnitude of cohort variation in size: cumulative vs. compensatory effects The curves of paired relative differences (Step 5; Fig. 6) were generally similar within a sex in a given population. From these curves, we computed the relative change from age to age in the magnitude of cohort variation in size between paired cohorts (Step 6; Fig. 7).

612 and sex and between age and generation time (Table 3b). Early in life, the relative change

613 from age to age was negative, corresponding to compensatory effects (Fig. 8). In general, 614 these compensatory effects rapidly decreased with age (sharp increase in the curves in

615 Fig. 8) and stopped just before mid-life (stabilizing around zero, implying neither

616 cumulative nor compensatory effects; Fig. 8). In males, however, compensatory effects 617 were weaker early in life compared with females, but continued throughout the lifetime, 618 decreasing only progressively with age (Fig. 8). Compensatory effects were stronger in 619 early life in species with a short generation time. In contrast, species with a long 620 generation time had a relative change from age to age that stabilized more rapidly, 
621 reaching a plateau close to zero at an earlier age relative to their lifetime (Fig. 8).

622 Comparing figures 6 and 7 reveals that the stabilization in species with a long generation time is mainly the result of a dissipation of cohort variation in size with increasing age, whereas cohort variation in size in species with a short generation time stabilized but was still present from mid-age to late life.

\section{Compensatory/catch-up growth vs. viability selection}

With the exception of mountain goats and reindeer, likelihood ratio tests revealed viability selection in all species, but not necessarily in both sexes or in all cohort clusters (Table 4). Overall, about half of the cohort clusters (Table 4) for both males (50\%, 13 of 26 cases) and females (52\%, 16 of 31 cases) showed evidence for viability selection. With the exception of Wind Cave bison, the coefficient for the effect of age at last measurement on body size (i.e. Step 2 including age at last measurement) was consistently positive, suggesting disappearance of lighter individuals with increasing age (e.g. males in Chizé, Fig. 9). Nevertheless, the relative change from age to age in the magnitude of cohort variation that was only due to differences in growth did not differ much from that due to both viability selection and growth (range of differences from 0 to $17.1 \%$ in the relative change from age to age after accounting for viability selection; Fig. 10). Overall, the change from age to age only due to differences in growth was influenced by the same variables as when including viability selection (Table 3b and 3c, Fig. 10), with the influence of age, sex and generation time showing very similar patterns (compare Fig. 8 and 10, which are on the same scale). The main difference was early in life, when the relative change from age to age only due to differences in growth was less than when the data included both viability selection and growth, particularly for shortlived species (blue and pink lines in Fig. 10). This effect was slightly stronger in males than in females (Fig. 10).

\section{DISCUSSION}

Based on an exceptional set of long-term data collected in 11 populations of large herbivores, we quantified cohort variation and assessed how it changed throughout life, demonstrating that this fundamental biological process varied both across species in 
relation to their pace of life and between sexes. Variation in size peaked at the start of life, then quickly decreased with increasing age in all species and stabilized around midlife. Even after accounting for viability selection, compensatory/catch-up growth was still a major process explaining the decrease in the amount of cohort variation with increasing age. Among-cohort variation was lower in species with a slower than a faster pace of life throughout the lifetime, and vanished at prime ages in the species with the slowest paces of life. Females showed less phenotypic variability and stronger compensatory/catch-up growth than males early in life, whereas males showed more progressive changes throughout life. This resulted in old males having the same low level of cohort variation as old females. Our findings concern mainly body mass variation because mass was used to describe body size in all except one species.

We found large variation in body size among cohorts in all species except the slowest species along the "slow-fast" continuum of life histories included in this study. Mixture models (McLachlan and Peel 2000), an innovative method to assess individual differences in life-history traits (Hamel et al. 2016), identified clusters of cohorts sharing similar body size at the start of life. We showed that cohort variation was structured, as opposed to the unstructured variation (i.e. uniform distribution) usually assumed when studying cohort effects with mixed models. This structured variation led to distinct growth trajectories throughout life among clusters of cohorts sharing similar initial size, in all species and most often in both sexes, thereby showing that early body size is a key driver of the growth trajectory later in life. Disentangling whether cohort-specific growth trajectories results from early or late environmental conditions is difficult without an experimental approach because individuals of the same cohort can experience the same environmental conditions throughout their entire lifetime (Metcalfe and Monaghan 2003). In this regard, one major novelty in our study is that we showed that environmental conditions experienced early in life per se, not just the cohort year modeled as a random effect term, typically have long-term consequences irrespective of late-life conditions. Indeed, cohort clusters with similar body size at the start of life included cohorts born in different years, and hence individuals included in the same cluster experienced different environmental conditions later in life. In many species, clusters included cohorts that 
were more than 20 years apart. Still, cohort clusters characterized by different initial body sizes displayed different growth trajectories throughout life, supporting the hypothesis that individual growth trajectories in large herbivores are considerably affected by early development. Of course, cohort variation does not account for all observed variation among body mass trajectories in a given population. The specific early mass of an individual, for instance, should markedly influence its future age-specific mass, as often reported for large herbivores (Clutton-Brock and Pemberton 2004, Douhard et al. 2013). Here, because individuals were not measured every year in several populations, we did not assess the contribution of individual variation in early mass to observed variation in age-specific mass later in life.

The greatest cohort variation in size occurs at the start of life, with on average a 20\% (up to $40 \%$ ) difference between cohort clusters. Cohort variation in size, however, decreased relatively rapidly with increasing age in all species. Our results indicate much potential for compensation in the magnitude of cohort variation in large herbivores despite limited time to compensate due to growth cessation at maturity. Nevertheless, the meta-analysis by Hector and Nakagawa (2012) pointed out that mammals and birds allocate more to accelerating growth after food restriction compared to fish and arthropods, possibly because species with determinate growth gain more benefits by compensating early, before growth ceases (Metcalfe and Monaghan 2003). The decreasing cohort variation with increasing age was a consequence of both higher survival of larger individuals, and compensatory/catch-up growth, which allowed some cohorts to partly make up for a poor start. Our results demonstrate that viability selection resulting from the positive influence of large size on individual survival is common in natural populations of large herbivores (Nussey et al. 2011). Nevertheless, although viability selection was detectable in almost all species and both sexes, it only explained a small fraction of the compensation in the magnitude of cohort variation, affecting mostly shorter-lived species. Viability selection is likely to peak during the neonatal stage in large herbivores, when survival is low and most variable (Gaillard et al. 2000b), and for many of our study populations it had likely already taken place when body size was first measured (Table 1). Consequently, our results imply that viability selection is influential, but that compensatory/catch-up growth 
714 is the main factor explaining the decrease in cohort variation with increasing age after the

715 neonatal stage.

716

717

Changes in growth patterns, either by increasing growth rate when conditions are better (compensatory growth) or by extending the growth period (catch-up growth), are likely to be selected whenever the ratio of benefits to costs is positive (Metcalfe and Monaghan 2001, Metcalfe and Monaghan 2003, Dmitriew 2011). Compensatory/catch-up growth should be selected when it enhances survival, both in the short-term, when it allows individuals to move out of a vulnerable stage, reducing mortality risk, and in the longterm, when large size buffers against environmental variation throughout life (Metcalfe and Monaghan 2003, Dmitriew 2011). Selection pressures for compensatory/catch-up growth are also high when large size improves reproductive success (Dmitriew 2011). In mammals, larger size provides competitive advantages to males of many species (Lidgard et al. 2005, Pelletier and Festa-Bianchet 2006, Mainguy et al. 2009), and generally also improves female reproductive success (Dobson et al. 1999, Hodge et al. 2008, Jones et al. 2010, Zedrosser et al. 2013, Plard et al. 2014b). On the other hand, compensatory/catchup growth can have short-term costs by reducing allocation to reproduction (MarcilFerland et al. 2013) or by increasing predation risk because of greater foraging time, and thereby exposure to predators (Dmitriew 2011). Faster or prolonged growth during development can also result in detectable trade-offs in other life-history traits later in life (Nussey et al. 2007, Dmitriew 2011, Douhard et al. 2014). For instance, according to the disposable soma theory (Kirkwood 1977), individuals allocating more to growth early in life are expected to pay a cost later in terms of reproduction or survival (Metcalfe and Monaghan 2001, Lemaître et al. 2015). Indeed, an increase in oxidative stress and in the repair of damaged cells can affect ageing patterns and longevity (Mangel and Munch 2005, Monaghan et al. 2009, Nussey et al. 2009, Dmitriew 2011), leading to subtle costs that might appear only late in life and hence might be under lower selection pressure (e.g. Lee et al. 2013b). The long-term trade-offs associated with growth during development are a cornerstone of life-history theory (Dmitriew 2011), and hence it is essential to assess how variation in individual growth changes with age to understand better its impact on individual fitness (Lee et al. 2013b). However, the relevance for population 
745 dynamics of subsequent changes in growth and trade-offs with life-history traits depends

746 on the survival of individuals from different cohorts. Given the documented potential

747 negative long-term fitness consequences of a poor start (reviewed in Metcalfe and

748 Monaghan 2001), the benefits, and thereby selection pressures, of compensating for a bad

749 start are likely to be high. This is supported by our finding that compensatory/catch-up

750 growth is a key process in the dissipation of cohort variation with increasing age. Hence,

751 the benefits/costs ratio for compensatory/catch-up growth is likely high in large

752 herbivores, with strong selection pressures for compensatory/catch-up growth in all

753 species irrespective of their pace of life.

Although compensatory effects were detected in all species, we found important differences among species in relation to their ranking on the "slow-fast" continuum of life histories. Cohort variation in size in early life was greater in species with a fast than a slow pace of life. This was supported by $i$ - our inability to detect any cohort variation in size in the African elephant, which had the longest generation time, $i i$ - the tendency to identify more cohort clusters in species with a fast than a slow pace of life, and iii- the greater relative differences in size among cohort clusters in species with a fast pace of life than in species with a slow pace of life. Long-lived species have evolved a slow pace of life: individuals generally show a conservative reproductive tactic that favors their own survival over that of their offspring because longevity increases fitness (Clutton-Brock 1988, Newton 1989). In these species, selection pressures have resulted in environmental canalization of adult survival, which shows lower variance than reproductive traits across a wide range of environmental conditions (Gaillard and Yoccoz 2003). Conversely, shortlived species have evolved a faster life-history strategy in which individuals allocate a high reproductive effort to each reproductive occasion, and environmental canalization has led to a lower variance in reproductive traits compared with long-lived species (Gaillard and Yoccoz 2003). The lower variance in growth at the start of life in long-lived than short-lived species suggests that initial growth is more affected by fluctuations in environmental conditions in species with a fast than a slow pace of life. This lower variance might also result from maternal effects, for example if mothers of longer-lived species provided more care to offspring, thereby buffering against environmental 
fluctuations. Although elephant mothers allocate to maternal care for a much longer period than any other large herbivore, the absolute time devoted to offspring by female elephant corresponds to the same allocation relative to their pace of life as other large herbivores included in our analysis (Langer 2008). Therefore, the lower variance in initial growth in long-lived species does not correspond to higher maternal investment in response to potentially higher time constraints. Moreover, maternal effects are unlikely to have a strong influence because mothers of long-lived species tend to favor their own survival at the expense of their offspring when resources are scarce (Sæther et al. 1993, Festa-Bianchet and Jorgenson 1998, Therrien et al. 2007, Martin and Festa-Bianchet 2010). Because body size is one of the main determinants of juvenile survival in most vertebrates including large herbivores (Plard et al. 2015, Théoret-Gosselin et al. 2015), our results suggest that body growth during development is likely to have been under strong selective pressures to promote survival, particularly in long-lived species.

Although cohort variation in size decreased markedly with increasing age and the strength of this decrease was similar across species, body size still varied among cohorts in short-lived species when they reached prime ages. In long-lived species, cohort variation almost totally vanished at the same life stage. Although compensatory/catch-up growth is relatively common, it is often incomplete (Metcalfe and Monaghan 2001, Dmitriew 2011). This is likely because of physiological constraints, where individuals are trapped in a developmental trajectory, or because the benefits/costs ratio is not high enough, and so growth rates are usually not maximal (Metcalfe and Monaghan 2003, Dmitriew 2011). Our results further suggest that there is a limited time window for compensatory/catch-up growth before prime age in species with determinate growth. Furthermore, cohorts of species with a fast pace of life were more variable in size early in life and, as the rate of decrease in cohort variation with increasing age was similar across species, they did not fully compensate/catch-up for initial size differences compared with species with a slow pace of life. With a limited time window and the costs paid later in life, the advantages of compensatory/catch-up growth should depend on its timing, with earlier compensatory/catch-up growth likely to be selected because of its direct benefits to survival and lifetime reproductive success (Dmitriew 2011). 
808 In addition to differences in cohort variation in size across species, we highlighted between-sex differences in cohort variation of large herbivores. Cohort variation in size was higher in early life in males than in females. Although the magnitude of cohort variation stabilized at mid-life in females, it continued to decrease progressively throughout lifetime in males, reaching the same level as that of females only at the end of life. Compensatory/catch-up growth, however, was stronger early in life in females and

814 stopped at mid-life compared with males that showed a weaker but constant

815 compensatory/catch-up growth throughout lifetime. These results likely emerged from

816 the contrasted sexual selection pressures in males and females in relation with sex

817 differences in intra-sexual competition (Bonduriansky et al. 2008). Indeed, although

818 sexual selection can be strong in females (Clutton-Brock 2007), selection for traits

819 affecting competitive abilities is generally stronger in males than in females, especially in

820 sexually size dimorphic and polygynous species such as large herbivores (Orians 1969,

821 Clutton-Brock 2007). Males and females adopt different tactics to increase their lifetime

822 reproductive success. The reproductive success of males is often highly skewed and

823 dependent on their ability to compete for reproductive opportunities (Orians 1969,

824 Trivers 1972). Thus, males often must fight to reproduce, and body size is a major

825 determinant of fighting and reproductive success (Lidgard et al. 2005, Pelletier and Festa-

826 Bianchet 2006, Mainguy et al. 2009). Females, on the other hand, usually compete for

827 resources (Orians 1969, Trivers 1972, Clutton-Brock 1991). Body size can therefore have

828 a stronger influence on the reproductive success of males than females, as shown in red

829 deer (Cervus elaphus; Kruuk et al. 1999). As a result of these differences in sexual

830 selection, males often evolve a "grow fast, die young" life-history strategy (Bonduriansky

831 et al. 2008), allocating more resources to rapid growth and fewer to maintenance (see e.g.

832 Toïgo et al. 1999 and Robinson et al. 2006). Males will therefore grow faster early in life

833 and for longer compared with females (Garel et al. 2006), thereby requiring more

834 nutrients than females (Michener and Locklear 1990, Landete-Castillejos et al. 2005).

835 Consequently, males are more sensitive to food shortage during early life and often show

836 greater juvenile mortality than females (Clutton-Brock et al. 1985). Greater vulnerability

837 to nutritional stress in males likely explains the larger cohort variation and the slightly 
stronger viability selection found in males than in females. Furthermore, even though males should have a shorter catch-up time window than females because they grow faster and die younger, compensatory/catch-up growth was much weaker and slower in males than in females. This pattern seems to confirm that even though it would be beneficial for males to compensate early in life, they have a lower ability to compensate/catch-up for a bad start than females (Toïgo et al. 1999, Festa-Bianchet et al. 2000, but see Solberg et al. 2008 and Rughetti and Festa-Bianchet 2010). Perhaps the costs of compensation/catch-up growth are greater for males, or small females can allocate more resources to growth by postponing primiparity (Martin and Festa-Bianchet 2012), an option that is not available to males.

\section{CONCLUSION}

The role of cohort variation as a process in life-history variation has often been explored. Our study, however, provides novel results on how the magnitude of cohort variation changes over the lifespan, and how these patterns vary among species in relation to the pace of life and between sexes. These topics have been neglected in previous studies likely because the required data for a comparative analysis were lacking until recently. We found that cohort variation in size decreased markedly during the first half of life and then almost vanished, particularly in species with a slow pace of life. Both compensatory/catch-up growth and viability selection dampened cohort variation in size with ageing, but compensatory/catch-up growth was the main underlying process beyond the neonatal stage. Our findings suggest that the costs associated with compensatory/catch-up growth are not necessarily high, at least early in life and particularly in females, or that the benefits are high. It remains to be determined whether differences in growth trajectories are adaptive. For instance, no study has yet tested whether delayed costs of rapid or prolonged early growth exist in wild vertebrates (see Lemaître et al. 2015 for a review). As fitness mostly depends on survival and reproductive success, which are both linked with body size (Dmitriew 2011), it is fundamental to evaluate the degree to which body size early in life and variability in developmental patterns among cohorts influence other traits later in life. 
869 Our study has shown that understanding how cohort variation changes over the lifetime

870 in wild populations reveals how selective forces affect populations and trait evolution.

871 Even though compensation is often assumed to occur in most species, its extent and the

872 eco-evolutionary mechanisms behind this process are often overlooked despite their

873 fundamental importance in population ecology (Metcalfe and Monaghan 2001, Metcalfe

874 and Monaghan 2003, Dmitriew 2011). For instance, climate change is predicted to result

875 in greater variability in environmental conditions (Easterling et al. 2000), likely

876 increasing variation among cohorts at the start of life (Stenseth et al. 2002). In this

877 context, only long-term studies can determine whether individuals within populations can

878 adapt to the increasing environmental variability brought by climate change. Unraveling

879 how variation changes with age, to what extent compensation occurs within populations,

880 and which eco-evolutionary processes are responsible for compensatory effects will

881 further our understanding of how future environmental changes may impact the

882 phenotypic composition of wild populations. Our comparative analysis provides the first

883 answers to these questions, by demonstrating the pervasiveness of cohort variation in size

884 in both sexes in populations of large herbivores distributed widely over the "slow-fast"

885 continuum of life histories, and by identifying how this cohort variation in size varies

886 with increasing age, highlighting the importance of both compensatory/catch-up growth

887 and viability selection.

\section{ACKNOWLEDGMENTS}

890 The mountain goat and bighorn sheep studies are mainly supported by the Natural

891 Sciences and Engineering Research Council of Canada and the Alberta Conservation

892 Association. The Svalbard reindeer project is mainly financed by the Norwegian

893 Research Council, NERC and The Hutton Institute. The Ravdol reindeer study is

894 financed by the Environmental Agency of Norway. The mouflon and roe deer projects

895 are supported by the Office National de la Chasse et de la Faune Sauvage. The Soay

896 sheep project was funded by NERC and supported by National Trust for Scotland; we

897 thank Josephine Pemberton and many other researchers involved in the project for access

898 to the data. Funding for the elephant growth was from ASAB, Carnegie Trust for

899 Universities of Scotland, and many private donors over 43 years. This contribution is part 
of the HETRAGE project supported by the FRIPRO program of the Norwegian Research Council (awarded to $\mathrm{SH}$ ). We are extremely grateful to the many people who helped collecting these invaluable data over all these years. We thank T. Coulson for comments on a previous draft of this manuscript. We are extremely grateful to T. Ezard, an anonymous reviewer, and the Associate Editor for providing constructive and insightful comments that greatly improved this paper.

\section{LITERATURE CITED}

Aitkin, M., B. Francis, J. Hinde, and R. Darnell. 2009. Statistical modelling in R. Oxford University Press.

Albon, S. D., T. H. Clutton-Brock, and F. E. Guinness. 1987. Early development and population dynamics in red deer. II. Density-independent effects and cohort variation. Journal of Animal Ecology 56:69-81.

Andersen, R., J.-M. Gaillard, J. D. C. Linnell, and P. Duncan. 2000. Factors affecting maternal care in an income breeder, the European roe deer. Journal of Animal Ecology 69:672-682.

Auer, S. K. 2010. Phenotypic plasticity in adult life-history strategies compensates for a poor start in life in trinidadian guppies (Puecilie reticulata). American Naturalist 176:818-829.

Bårdsen, B.-J., and T. Tveraa. 2012. Density-dependence vs. density-independence linking reproductive allocation to population abundance and vegetation greenness. Journal of Animal Ecology 81:364-376.

Baron, J.-P., J.-F. Le Galliard, T. Tully, and R. Ferrière. 2010. Cohort variation in offspring growth and survival: prenatal and postnatal factors in a late-maturing viviparous snake. Journal of Animal Ecology 79:640-649.

Bates, D., M. Maechler, and B. M. Bolker. 2014. lme4: Linear mixed-effects models using Eigen and S4.

Bates, D., M. Mächler, B. M. Bolker, and S. C. Walker. 2015. Fitting linear mixed-effects models using lme4. Journal of Statististical Software 67:1-48.

Bateson, P., D. Barker, T. Clutton-Brock, D. Deb, B. D'Udine, R. A. Foley, P. Gluckman, K. Godfrey, T. Kirkwood, M. M. Lahr, J. McNamara, N. B. Metcalfe, P. Monaghan, H. 
G. Spencer, and S. E. Sultan. 2004. Developmental plasticity and human health. Nature 430:419-421.

Bernardo, J. 1996. Maternal effects in animal ecology. American Zoologist 36:83-105.

Bonduriansky, R., A. Maklakov, F. Zajitschek, and R. Brooks. 2008. Sexual selection, sexual conflict and the evolution of ageing and life span. Functional Ecology 22:443453.

Brame, R., D. S. Nagin, and L. Wasserman. 2006. Exploring some analytical characteristics of finite mixture models. Journal of Quantitative Criminology 22:31-59.

Caswell, H. 2001. Matrix population models: construction, analysis, and interpretation. 2nd edition. Sinauer Associates, Sunderland, Massachusetts.

Christiansen, P. 2004. Body size in proboscideans, with notes on elephant metabolism. Zoological Journal of the Linnean Society 140:523-549.

Clutton-Brock, T. 2007. Sexual selection in males and females. Science 318:1882-1885.

Clutton-Brock, T. H. 1988. Reproductive success: studies of individual variation in contrasting breeding systems. University of Chicago Press, Chicago.

Clutton-Brock, T. H. 1991. The evolution of parental care. Princeton University Press, Princeton, New Jersey.

Clutton-Brock, T. H., S. D. Albon, and F. E. Guinness. 1985. Parental investment and sex differences in juvenile mortality in birds and mammals. Nature 313:131-133.

Clutton-Brock, T. H., and J. M. Pemberton. 2004. Soay sheep: dynamics and selection in an island population. Cambridge University Press, Cambridge.

Clutton-Brock, T. H., I. R. Stevenson, P. Marrow, A. D. MacColl, A. I. Houston, and J. M. McNamara. 1996. Population fluctuations, reproductive costs and life-history tactics in female Soay sheep. Journal of Animal Ecology 65:675-689.

Coulson, T., and S. Tuljapurkar. 2008. The dynamics of a quantitative trait in an agestructured population living in a variable environment. American Naturalist 172:599612.

Crowley, P.H., and K. R. Hopper. 2015. Mechanisms for adaptive cohort splitting. Ecological Modelling 308:1-13. 
Cubaynes, S., C. Lavergne, E. Marboutin, and O. Gimenez. 2012. Assessing individual heterogeneity using model selection criteria: how many mixture components in capturerecapture models? Methods in Ecology and Evolution 3:564-573.

Descamps, S., S. Boutin, D. Berteaux, A. G. McAdam, and J.-M. Gaillard. 2008. Cohort effects in red squirrels: the influence of density, food abundance and temperature on future survival and reproductive success. Journal of Animal Ecology 77:305-314.

Dmitriew, C. M. 2011. The evolution of growth trajectories: what limits growth rate? Biological Reviews 86:97-116.

Dobson, F. S., T. S. Risch, and J. O. Murie. 1999. Increasing returns in the life history of Columbian ground squirrels. Journal of Animal Ecology 68:73-86.

Douhard, M., J.-M. Gaillard, D. Delorme, G. Capron, P. Duncan, F. Klein, and C. Bonenfant. 2013. Variation in adult body mass of roe deer: early environmental conditions influence early and late body growth of females. Ecology 94:1805-1814.

Douhard, M., F. Plard, J.-M. Gaillard, G. Capron, D. Delorme, F. Klein, P. Duncan, L. E. Loe, and C. Bonenfant. 2014. Fitness consequences of environmental conditions at different life stages in a long-lived vertebrate. Proceedings of the Royal Society B 281:20140276.

Easterling, D. R., G. A. Meehl, C. Parmesan, S. A. Changnon, T. R. Karl, and L. O. Mearns. 2000. Climate extremes: observations, modeling, and impacts. Science 289:2068-2074.

Everitt, B. S., S. Landau, M. Leese, and D. Stahl. 2011. Cluster analysis. 5th edition. John Wiley \& Sons.

Festa-Bianchet, M., and S. D. Côté. 2008. Mountain goats: ecology, behavior and conservation of an alpine ungulate. Island Press, Washington.

Festa-Bianchet, M., and J. T. Jorgenson. 1998. Selfish mothers: reproductive expenditure and resource availability in bighorn ewes. Behavioral Ecology 9:144-150.

Festa-Bianchet, M., J. T. Jorgenson, and D. Réale. 2000. Early development, adult mass, and reproductive success in bighorn sheep. Behavioral Ecology 11:633-639.

Fisher, R. A. 1930. The genetical theory of natural selection. The Clarendon Press, Oxford, England. 
Ford, J. H., M. V. Bravington, and J. Robbins. 2012. Incorporating individual variability into mark-recapture models. Methods in Ecology and Evolution 3:1047-1054.

Frühwirth-Schnatter, S. 2006. Finite mixture and Markov switching models. Springer, New York, USA.

Gaillard, J.-M., P. Duncan, D. Delorme, G. Van Laere, N. Pettorelli, D. Maillard, and G. Renaud. 2003a. Effects of hurricane Lothar on the population dynamics of European roe deer. Journal of Wildlife Management 67:767-773.

Gaillard, J.-M., M. Festa-Bianchet, D. Delorme, and J. Jorgenson. 2000a. Body mass and individual fitness in female ungulates: bigger is not always better. Proceedings of the Royal Society B 267:471-477.

Gaillard, J.-M., M. Festa-Bianchet, N. G. Yoccoz, A. Loison, and C. Toïgo. 2000b. Temporal variation in fitness components and population dynamics of large herbivores. Annual Review of Ecology and Systematics 31:367-393.

Gaillard, J.-M., J.-F. Lemaître, V. Berger, C. Bonenfant, S. Devillard, M. Douhard, M. Gamelon, F. Plard, and J.-D. Lebreton. 2016. Life histories, axes of variation in. In R. M. Kliman, editor, Encyclopedia of Evolutionary Biology 2:312-323. Gaillard, J.-M., A. Loison, C. Toïgo, D. Delorme, and G. V. Laere. 2003b. Cohort effects and deer populaton dynamics. Ecoscience 10:412-420.

Gaillard, J.-M., and N. G. Yoccoz. 2003. Temporal variation in survival of mammals: a case of environmental canalization? Ecology 84:3294-3306.

Gaillard, J.-M., N. G. Yoccoz, J.-D. Lebreton, C. Bonenfant, S. Devillard, A. Loison, D. Pontier, and D. Allainé. 2005. Generation time: A reliable metric to measure lifehistory variation among mammalian populations. American Naturalist 166:119-123. Garel, M., J.-M. Cugnasse, J.-M. Gaillard, A. Loison, P. Gibert, P. Douvre, and D. Dubray. 2005. Reproductive output of female mouflon (Ovis gmelini musimon x Ovis sp.): a comparative analysis. Journal of Zoology 266:65-71.

Garel, M., J.-M. Cugnasse, D. Maillard, J.-M. Gaillard, A. J. M. Hewison, and D. Dubray. 2007. Selective harvesting and habitat loss produce long-term life history changes in a mouflon population. Ecological Applications 17:1607-1618. 
1019 Garel, M., E. J. Solberg, B.-E. Saether, I. Herfindal, and K.-A. Hogda. 2006. The length

1020 of growing season and adult sex ratio affect sexual size dimorphism in moose. Ecology $1021 \quad 87: 745-758$.

1022 Garratt, M., J.-F. Lemaître, M. Douhard, C. Bonenfant, G. Capron, C. Warnant, F. Klein, 1023 R. C. Brooks, and J.-M. Gaillard. 2015. High juvenile mortality is associated with sexspecific adult survival and lifespan in wild roe deer. Current Biology 25:759-763.

1025

Grafen, A. 1988. On the uses of data on lifetime reproductive success. Pages 454-471 in T. H. Clutton-Brock, editor. Reproductive success. University of Chicago Press, Chicago.

Green, W.C.H., and A. Rothstein. 1991. Trade-offs between growth and reproduction in female bison. Oecologia 86:521-527.

Grün, B., and F. Leisch. 2008. FlexMix version 2: finite mixtures with concomitant variables and varying and constant parameters. Journal of Statistical Software 28:1-35.

Hamel, S., S. D. Côté, and M. Festa-Bianchet. 2010. Maternal characteristics and environment affect the costs of reproduction in female mountain goats. Ecology 91:2034-2043.

Hamel, S., J. M. Craine, and E. G. Towne. 2012. Maternal allocation in bison: cooccurrence of senescence, cost of reproduction, and individual quality. Ecological Applications 22:1628-1639.

Hamel, S., N. G. Yoccoz, and J.-M. Gaillard. 2016. Assessing variation in life-history tactics within a population using mixture regression models: a practical guide for evolutionary ecologists. Biological Reviews, In press.

Hastings, K. K., L. A. Jemison, T. S. Gelatt, J. L. Laake, G. W. Pendleton, J. C. King, A. W. Trites, and K. W. Pitcher. 2011. Cohort effects and spatial variation in age-specific survival of Steller sea lions from southeastern Alaska. Ecosphere 2:Art 111.

Hayward, A. D., I. J. Rickard, and V. Lummaa. 2013. Influence of early-life nutrition on mortality and reproductive success during a subsequent famine in a preindustrial population. Proceedings of the National Academy of Science USA 110:13886-13891.

Hector, K. L., and S. Nakagawa. 2012. Quantitative analysis of compensatory and catchup growth in diverse taxa. Journal of Animal Ecology 81:583-593. 
1049 Herfindal, I., M. van de Pol, J. T. Nielsen, B.-E. Sæther, and A. P. Møller. 2015. Climatic 1050 conditions cause complex patterns of covariation between demographic traits in a long-

1051

1052

1053

1054

1055

1056

1057

1058

1059

1060

1061

1062

1063

1064

1065

1066

1067

1068

1069

1070

1071

1072

1073

1074

1075

1076

1077

1078

1079 lived raptor. Journal of Animal Ecology 84:702-711.

Hodge, S. J., A. Manica, T. P. Flower, and T. H. Clutton-Brock. 2008. Determinants of reproductive success in dominant female meerkats. Journal of Animal Ecology 77:92102.

Hoeksma, J. B., and H. Kelderman. 2006. On growth curves and mixture models. Infant and Child Development 15:627-634.

Jones, B. L., D. S. Nagin, and K. Roeder. 2001. A SAS procedure based on mixture models for estimating developmental trajectories. Sociological Methods and Research 29:374-393.

Jones, J. H., M. L. Wilson, C. Murray, and A. Pusey. 2010. Phenotypic quality influences fertility in Gombe chimpanzees. Journal of Animal Ecology 79:1262-1269.

Jones, O. R., J.-M. Gaillard, S. Tuljapurkar, J. S. Alho, K. B. Armitage, P. H. Becker, P. Bize, J. Brommer, A. Charmantier, M. Charpentier, T. Clutton-Brock, F. S. Dobson, M. Festa-Bianchet, L. Gustafsson, H. Jensen, C. G. Jones, B.-G. Lillandt, R. McCleery, J. Merilä, P. Neuhaus, M. A. C. Nicoll, K. Norris, M. K. Oli, J. Pemberton, H. Pietiäinen, T. H. Ringsby, A. Roulin, B.-E. Sæther, J. M. Setchell, B. C. Sheldon, P. M.

Thompson, H. Weimerskirch, E. J. Wickings, and T. Coulson. 2008. Senescence rates are determined by ranking on the fast-slow life-history continuum. Ecology Letters 11:664-673.

Jönsson, K. I. 1997. Capital and income breeding as alternative tactics of resource use in reproduction. Oikos 78:57-66.

Kirkwood, T,B. L. 1977. Evolution of ageing. Nature 270:301-304.

Kruuk, L. E. B., T. H. Clutton-Brock, K. E. Rose, and F. E. Guinness. 1999. Early determinant of lifetime reproductive success differ between the sexes in red deer. Proceedings of the Royal Society B 266:1655-1661.

Landete-Castillejos, T., A. Garcia, F. R. Lopez-Serrano, and L. Gallego. 2005. Maternal quality and differences in milk production and composition for male and female Iberian red deer calves (Cervus elaphus hispanicus). Behavioral Ecology and Sociobiology 57:267-274.

This article is protected by copyright. All rights reserved 
1080 Langer, P. 2008. The phases of maternal investment in eutherian mammals. Zoology $1081 \quad 111: 148-162$.

1082 Laws, R. M., Parker, I. S. C., and R. C. B. Johnstone. 1975. Elephants and their habitats:

1083 the ecology of elephants in North Bunyoro, Uganda. Clarendon Press.

1084 Le Galliard, J.-F., O. Marquis, and M. Massot. 2010. Cohort variation, climate effects

1085 and population dynamics in a short-lived lizard. Journal of Animal Ecology 79:1296-

10861307.

1087 Lee, P. C., L. F. Bussière, C. E. Webber, J. H. Poole, and C. J. Moss. 2013a. Enduring

1088 consequences of early experiences: 40 year effects on survival and success among

1089 African elephants (Loxodonta africana). Biology Letters 9:20130011.

1090 Lee, W.-S., P. Monaghan, and N. B. Metcalfe. 2013b. Experimental demonstration of the

1091 growth rate-lifespan trade-off. Proceedings of the Royal Society B 280:20122370.

1092 Lemaître, J.-F., V. Berger, C. Bonenfant, M. Douhard, M. Gamelon, F. Plard, and J.-M.

1093 Gaillard. 2015. Early-late life trade-offs and the evolution of ageing in the wild.

1094 Proceedings of the Royal Society B 282:20150209.

1095 Leslie, P. H. 1966. The intrinsic rate of increase and the overlap of successive generations

1096 in a population of guillemots (Uria aalge Pont.). Journal of Animal Ecology 35:291-

1097301.

1098 Lidgard, D. C., D. J. Boness, W. D. Bowen, and J. I. McMillan. 2005. State-dependent

1099 male mating tactics in the grey seal: the importance of body size. Behavioral Ecology

$1100 \quad 16: 541-549$.

1101 Lindström, J. 1999. Early development and fitness in birds and mammals. Trends in

1102 Ecology and Evolution 14:343-348.

1103 Lindström, J., and H. Kokko. 2002. Cohort effects and population dynamics. Ecology

1104 Letters 5:338-344.

1105 Madsen, T., and R. Shine. 2000. Silver spoons and snake body sizes: prey availability

1106 early in life influences long-term growth rates of free-ranging pythons. Journal of

1107 Animal Ecology 69:952-958.

1108 Mainguy, J., S. D. Côté, M. Festa-Bianchet, and D. W. Coltman. 2009. Father-offspring

1109 phenotypic correlations suggest intralocus sexual conflict for a fitness-linked trait in a

1110 wild sexually dimorphic mammal. Proceedings of the Royal Society B 276:4067-4075. 
1111 Mangel, M., and S. B. Munch. 2005. A life-history perspective on short- and long-term

1112 consequences of compensatory growth. American Naturalist 166:E155-E176.

1113 Marcil-Ferland, D., M. Festa-Bianchet, A. M. Martin, and F. Pelletier. 2013. Despite

1114 catch-up, prolonged growth has detrimental fitness consequences in a long-lived

1115 vertebrate. American Naturalist 182:775-785.

1116 Martin, J. G. A., and M. Festa-Bianchet. 2010. Bighorn ewes transfer the costs of

1117 reproduction to their lambs. American Naturalist 176:414-423.

1118 Martin, J. G. A., and M. Festa-Bianchet. 2012. Determinants and consequences of age of

1119 primiparity in bighorn ewes. Oikos 121:752-760.

1120 McLachlan, G. J. 1987. On bootstrapping the likelihood ratio test statistic for the number

1121 of components in a normal mixture. Journal of the Royal Statistical Society C 36:318-

1122324.

1123 McLachlan, G. J., and D. Peel. 2000. Finite mixture models. John Wiley \& Sons.

1124 McLachlan, G. J., and S. Rathnayake. 2014. On the number of components in a Gaussian

1125 mixture model. WIREs Data Mining and Knowledge Discovery 4:341-355.

1126 McNamara, J. 1998. Phenotypic plasticity in fluctuating environments: consequences of

1127 the lack of individual optimization. Behavioral Ecology 9:642-648.

1128 McNamara, J. M., and A. I. Houston. 1996. State-dependent life histories. Nature

$1129 \quad 380: 215-221$.

1130 Melnykov, V. 2013. Challenges in model-based clustering. WIREs Computational

$1131 \quad$ Statistics 5:135-148.

1132 Metcalfe, N.B., and P. Monaghan. 2003. Growth versus lifespan: perspectives from

1133 evolutionary ecology. Experimental Gerontology 38:935-940.

1134 Metcalfe, N. B., and P. Monaghan. 2001. Compensation for a bad start: grow now, pay

1135 later? Trends in Ecology and Evolution 16:254-260.

1136 Michener, G. R., and L. Locklear. 1990. Differential costs of reproductive effort for male

1137 and female Richardson's ground squirrels. Ecology 71:855-868.

1138 Monaghan, P. 2008. Early growth conditions, phenotypic development and

1139 environmental change. Philosophical Transactions of the Royal Society B 363:1635-

$1140 \quad 1645$.

This article is protected by copyright. All rights reserved 
1141 Monaghan, P., N. B. Metcalfe, and R. Torres. 2009. Oxidative stress as a mediator of life

1142 history trade-offs: mechanisms, measurements and interpretation. Ecology Letters $1143 \quad 12: 75-92$.

1144 Moss, C. J., H. Croze, and P. C. Lee. 2011. The Amboseli elephants: a long-term

1145 perspective on a long-lived mammal. The University of Chicago Press, Chicago.

1146 Mousseau, T. A., and C. W. Fox. 1998. The adaptive significance of maternal effects.

1147 Trends in Ecology and Evolution 13:403-407.

1148 Newton, I. 1989. Lifetime reproduction in birds. Academic Press, London, Toronto.

1149 Nussey, D. H., L. E. B. Kruuk, A. Morris, and T. H. Clutton-Brock. 2007. Environmental

1150 conditions in early life influence ageing rates in a wild population of red deer. Current

1151 Biology 17:R1000-R1001.

1152 Nussey, D. H., J. M. Pemberton, J. G. Pilkington, and J. D. Blount. 2009. Life history

1153 correlates of oxidative damage in a free-living mammal population. Functional Ecology

$1154 \quad 23: 809-817$.

1155 Nussey, D. H., T. Coulson, D. Delorme, T. H. Clutton-Brock, J. M. Pemberton, M. Festa-

1156 Bianchet, and J.-M. Gaillard. 2011. Patterns of body mass senescence and selective

1157 disappearance differ among three species of free-living ungulates. Ecology 92:1936-

$1158 \quad 1947$.

1159 Orians, G. H. 1969. On the evolution of mating systems in birds and mammals. American

$1160 \quad$ Naturalist 103:589-603.

1161 Ozgul, A., S. Tuljapurkar, T. G. Benton, J. M. Pemberton, T. H. Clutton-Brock, and T.

1162 Coulson. 2009. The dynamics of phenotypic change and the shrinking sheep of St.

1163 Kilda. Science 325:464-467.

1164 Pelletier, F., and M. Festa-Bianchet. 2006. Sexual selection and social rank in bighorn

1165 rams. Animal Behaviour 71:649-655.

1166 Pettorelli, N., J.-M. Gaillard, G. V. Laere, P. Duncan, P. Kjellander, O. Liberg, D.

1167 Delorme, and D. Maillard. 2002. Variations in adult body mass in roe deer: the effects

1168 of population density at birth and of habitat quality. Proceedings of the Royal Society B

$1169269: 747-753$. 
1170 Plard, F., J.-M. Gaillard, T. Coulson, A. J. M. Hewison, D. Delorme, C. Warnant, and C.

1171 Bonenfant. 2014a. Mismatch between birth date and vegetation phenology slows the

1172 demography of roe deer. Plos Biology 12:e1001828.

1173 Plard, F., J.-M. Gaillard, T. Coulson, A. J. M. Hewison, D. Delorme, C. Warnant, E. B.

1174 Nilsen, and C. Bonenfant. 2014b. Long-lived and heavier females give birth earlier in

1175 roe deer. Ecography 37:214-249.

1176 Plard, F., N. G. Yoccoz, C. Bonenfant, F. Klein, C. Warnant, and J.-M. Gaillard. 2015.

1177 Disentangling direct and growth-mediated influences on early survival: a mechanistic

1178 approach. Journal of Animal Ecology 84:1363-1372.

1179 Robertson, A., M. Hiraiwa-Hasegawa, S. D. Albon, and T. H. Clutton-Brock. 1992. Early

1180 growth and sucking behaviour of Soay sheep in a fluctuating population. Journal of

1181 Zoology 227:661-671.

1182 Robinson, M. R., J. G. Pilkington, T. H. Clutton-Brock, J. M. Pemberton, and L. E. B.

1183 Kruuk. 2006. Live fast, die young: trade-offs between fitness components and sexually

1184 antagonistic selection on weaponry in Soay sheep. Evolution 60:2168-2181.

1185 Rughetti, M., and M. Festa-Bianchet. 2010. Compensatory growth limits opportunities

1186 for artificial selection in Alpine chamois. Journal of Wildlife Management 74:1024-

$1187 \quad 1029$.

1188 Sæther, B.-E., R. Andersen, and H. C. Pedersen. 1993. Regulation of parental effort in a

1189 long-lived seabird: an experimental manipulation of the cost of reproduction in the

1190 antarctic petrel, Thalassoica antarctica. Behavioural Ecology and Sociobiology 33:147-

1191150.

1192 Sæther, B.-E., T. Coulson, V. Grøtan, S. Engen, R. Altwegg, K. B. Armitage, C.

1193 Barbraud, P. H. Becker, D. T. Blumstein, F. S. Dobson, M. Festa-Bianchet, J.-M.

1194 Gaillard, A. Jenkins, C. Jones, M. A. C. Nicoll, K. Norris, M. K. Oli, A. Ozgul, and H.

1195 Weimerskirch. 2013. How life history influences population dynamics in fluctuating

1196 environments. American Naturalist 182:743-759.

1197 Schielzeth, H., and W. Forstmeier. 2009. Conclusions beyond support: overconfident

1198 estimates in mixed models. Behavioral Ecology 20:416-420. 
1199 Solberg, E. J., M. Garel, M. Heim, V. Grøtan, and B.-E. Sæther. 2008. Lack of

1200 compensatory body growth in a high performance moose Alces alces population.

1201 Oecologia 158:485-498.

1202 Solberg, E. J., M. Heim, V. Grøtan, B.-E. Sæther, and M. Garel. 2007. Annual variation

1203 in maternal age and calving date generate cohort effects in moose (Alces alces) body

1204 mass. Oecologia 154:259-271.

1205 Solberg, E. J., A. Loison, J.-M. Gaillard, and M. Heim. 2004. Lasting effects of

1206 conditions at birth on moose body mass. Ecography 27:677-687.

1207 Stahl, D., and H. Sallis. 2012. Model-based cluster analysis. WIREs Computational

1208 Statistics 4:341-358.

1209 Stamps, J. A., M. Briffa, and P. A. Biro. 2012. Unpredictable animals: individual

1210 differences in intraindividual variability (IIV). Animal Behaviour 83:1325-1334.

1211 Stearns, S. C. 1976. Life history tactics: a review of the ideas. Quarterly Review of

1212 Biology 51:3-47.

1213 Stearns, S. C. 1983. The influence of size and phylogeny on patterns of covariation

1214 among life-history traits in the mammals. Oikos 41:173-187.

1215 Steinheim, G., A. Mysterud, Ø. Holand, M. Bakken, and T. Adnøy. 2002. The effect of

1216 initial weight of the ewe on later reproductive effort in domestic sheep (Ovis aries).

1217 Journal of Zoology 258:515-520.

1218 Stenseth, N. C., A. Mysterud, G. Ottersen, J. W. Hurrell, K.-S. Chan, and M. Lima. 2002.

1219 Ecological effects of climate fluctuations. Science 297:1292-1296.

1220 Stien, A., R. J. Irvine, E. Ropstad, O. Halvorsen, R. Langvatn, and S. D. Albon. 2002.

1221 The impact of gastrointestinal nematodes on wild reindeer: experimental and cross-

1222 sectional studies. Journal of Animal Ecology 71:937-945.

1223 Suarez,O. V., M. Busch, and F. O. Kravetz. 2004. Reproductive strategies in Akodon

1224 azarae (Rodentia, Muridae). Canadian Journal of Zoology 82:1572-1577.

1225 Théoret-Gosselin, R., S. Hamel, and S. D. Côté. 2015. The role of maternal behavior and

1226 offspring development in the survival of mountain goat kids. Oecologia 178:175-186.

1227 Therrien, J.-F., S. D. Côté, M. Festa-Bianchet, and J.-P. Ouellet. 2007. Conservative

1228 maternal care in an iteroparous mammal: a resource allocation experiment. Behavioural

$1229 \quad$ Ecology and Sociobiology 62:193-199.

This article is protected by copyright. All rights reserved 
1230 Thomas, D. W., J. Blondel, P. Perret, M. M. Lambrechts, and J. R. Speakman. 2001.

1231 Energetic and fitness costs of mismatching resource supply and demand in seasonally

1232 breeding birds. Science 291:2598-2600.

1233 Toïgo, C., J.-M. Gaillard, and J. Michallet. 1999. Cohort affects growth of males but not

1234 females in Alpine ibex (Capra ibex ibex). Journal of Mammalogy 80:1021-1027.

1235 Trivers, R. L. 1972. Parental investment and sexual selection. Pages 138-179 in B.

1236 Campbell, editor. Sexual selection and the descent of man. Aldine Publishing

1237 Company, Chicago, Illinois.

1238 Tuljapurkar, S., U. K. Steiner, and S. H. Orzack. 2009. Dynamic heterogeneity in life

1239 histories. Ecology Letters 12:93-106.

1240 van de Pol, M., L. W. Bruinzeel, D. Heg, H. P. van der Jeugd, and S. Verhulst. 2006. A

1241 silver spoon for a golden future: long-term effects of natal origin on fitness prospects of

1242 oystercatchers (Haematopus ostralegus). Journal of Animal Ecology 75:616-626.

1243 van de Pol, M., and S. Verhulst. 2006. Age-dependent traits: a new statistical model to

1244 separate within- and between-individual effects. American Naturalist 167:766-773.

1245 van de Pol, M., and J. Wright. 2009. A simple method for distinguishing within- versus

1246 between-subject effects using mixed models. Animal Behaviour 77:753-758.

1247 Vaupel, J. W., K. G. Manton, and E. Stallard. 1979. The impact of heterogeneity in

1248 individual frailty on the dynamics of mortality. Demography 16:439-454.

1249 Venables, W. N., and B. D. Ripley. 2002. Modern applied statistics with S. Springer,

1250 New York.

1251 Verbeke, G., and E. Lesaffre. 1996. A linear mixed-effects model with heterogeneity in

1252 the random-effects population. Journal of the American Statistical Association 91:217-

1253221.

1254 Wilkin, T. A., and B. C. Sheldon. 2009. Sex differences in the persistence of natal

1255 environmental effects on life histories. Current Biology 19:1998-2002.

1256 Wilson, A. J., J. M. Pemberton, J. G. Pilkington, T. H. Clutton-Brock, and L. E. B.

1257 Kruuk. 2009. Trading offspring size for number in a variable environment: selection on

1258 reproductive investment in female Soay sheep. Journal of Animal Ecology 78:354-364.

1259 Wooller, R. D., J. S. Bradley, and J. P. Croxall. 1992. Long-term population studies of

1260 seabirds. Trends in Ecology and Evolution 7:111-114. 
1261 Zedrosser, A., F. Pelletier, R. Bischof, M. Festa-Bianchet, and J. E. Swenson. 2013.

1262 Determinants of lifetime reproduction in female brown bears: early body mass,

1263 longevity, and hunting regulations. Ecology 94:231-240.

1264

1265

1266

1267

1268

1269

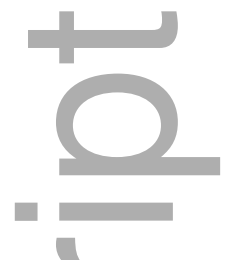

\section{Data Availability}

1270

Data associated with this paper have been deposited in Dryad:

http://dx:doi.org/10.5061/dryad.n358r
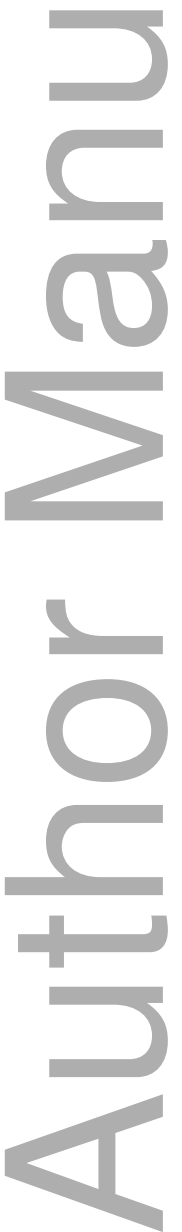

This article is protected by copyright. All rights reserved 
Table 1. Summary of populations monitored and data available for the comparative analysis of cohort variation in size in large herbivores.

\begin{tabular}{|c|c|c|c|c|c|c|c|c|c|c|c|}
\hline Population & Species & Location & Years & $\mathrm{N}$ males ${ }^{\&}$ & $\mathrm{~N}$ females ${ }^{\&}$ & $\begin{array}{l}\text { Body size } \\
\text { measure }\end{array}$ & Age $^{\varnothing}$ & $\mathrm{N}$ & $\begin{array}{r}K \\
{\left[\mathrm{R}^{2}\right]}\end{array}$ & GT & References \\
\hline \multirow[t]{3}{*}{ Amboseli } & African elephants & Kenya & $1972-2008 *$ & 88 & 87 & Shoulder & $0-4.5^{\Delta}$ & 25 & 1 & 19.78 & 1 \\
\hline & Loxodonta africana & & & 249 [319] & $280[440]$ & height & & & {$[0]$} & & \\
\hline & & & & $1.3[1-5]$ & $1.6[1-5]$ & & & & & & \\
\hline \multirow[t]{3}{*}{ Caw Ridge } & Mountain goats & Alberta, & 1989-2013 & 132 & 124 & Mass in & 1 & 25 & 2 & 10.96 & 2,3 \\
\hline & Oreamnos americanus & Canada & & $164[453]$ & $159[761]$ & July & & & {$[0.28]$} & & \\
\hline & & & & $2.8[1-8]$ & $4.8[1-13]$ & & & & & & \\
\hline \multirow[t]{3}{*}{ Konza Prairie } & Plains bison & Kansas, & 1994-2012 & 664 & 634 & Mass in & 0 & 19 & 4 & 9.37 & 4 \\
\hline & Bison bison & USA & & 709 [2074] & 709 [2714] & November & & & {$[0.87]$} & & \\
\hline & & & & $2.9[1-9]$ & $3.8[1-17]$ & & & & & & \\
\hline \multirow{2}{*}{ Wind Cave } & Plains bison & South Dakota, & $1966-2008 *$ & 931 & 868 & Mass in & 1 & 26 & 5 & 9.37 & 5 \\
\hline & Bison bison & USA & & 1251 [1509] & 1187 [2491] & November & & & {$[0.93]$} & & \\
\hline & & & & $1.2[1-5]$ & $2.1[1-18]$ & & & & & & \\
\hline \multirow{3}{*}{ Ram Mountain } & Bighorn sheep & Alberta, & $1973-2013$ & 268 & 299 & Mass in & 1 & 41 & 3 & 8.57 & 6 \\
\hline & Ovis canadensis & Canada & & $477[1511]$ & 484 [2369] & September & & & {$[0.65]$} & & \\
\hline & & & & $3.2[1-13]$ & $4.9[1-20]$ & & & & & & \\
\hline \multirow[t]{3}{*}{ Svalbard } & Svalbard reindeer & Svalbard & 1994-2013 & - & 552 & Mass in & 0 & 20 & 3 & 6.67 & 7 \\
\hline & Rangifer tarandus & & & - & 618 [1953] & Feb-May & & & {$[0.58]$} & & \\
\hline & platyrhynchus & & & - & $3.2[1-10]$ & & & & & & \\
\hline \multirow{2}{*}{ Ravdol } & Reindeer & Finnmark, & 2002-2014 & - & 330 & Mass in & 0 & 13 & 2 & 5.15 & 8 \\
\hline & Rangifer tarandus & Norway & & - & 374 [1298] & September & & & {$[0.40]$} & & \\
\hline
\end{tabular}




\begin{tabular}{|c|c|c|c|c|c|c|c|c|c|c|c|}
\hline & & & & - & $3.5[1-12]$ & & & & & & \\
\hline \multirow[t]{3}{*}{ Chizé } & Roe deer & Southwestern & 1977-2012 & 571 & 510 & Mass in & 1 & 36 & 3 & 4.6 & $9,10,11$ \\
\hline & Capreolus capreolus & France & & 607 [1447] & 543 [1682] & Jan-Feb & & & {$[0.47]$} & & \\
\hline & & & & $2.4[1.13]$ & $3.1[1-14]$ & & & & & & \\
\hline \multirow[t]{3}{*}{ Trois Fontaines } & Roe deer & Northeastern & $1975-2012$ & 361 & 365 & Mass in & 1 & 38 & 3 & 4.6 & $9,10,12$ \\
\hline & Capreolus capreolus & France & & 465 [1055] & 450 [1352] & Jan-Feb & & & {$[0.43]$} & & \\
\hline & & & & 2.3 [1-9] & $3.0[1-10]$ & & & & & & \\
\hline \multirow[t]{3}{*}{ St. Kilda } & Soay sheep & Hirta Island, & $1985-2013 *$ & 943 & 982 & Mass in & 0 & 28 & 4 & 4.47 & 13 \\
\hline & Ovis aries & Scotland & & 1364 [2097] & $1565[3940]$ & August & & & {$[0.34]$} & & \\
\hline & & & & $1.5[1-11]$ & $2.5[1-14]$ & & & & & & \\
\hline \multirow[t]{3}{*}{ Caroux } & Mouflon & Massif Central, & $1995-2014$ & 459 & 401 & Mass in & 0 & 20 & 3 & 4.21 & 14,15 \\
\hline & Ovis gmelini musimon & France & & $643[850]$ & 523 [757] & May-June & & & {$[0.27]$} & & \\
\hline & $\times$ Ovis sp. & & & $1.3[1-7]$ & $1.4[1-10]$ & & & & & & \\
\hline
\end{tabular}

\footnotetext{
* The range of years is higher than the number of cohorts available $(\mathrm{N})$ either because data were not collected in all years, or because measurements at first age were not collected in all years.

${ }^{\&}$ Top row is the number of individuals measured at first age (i.e. used in Step 1, see Methods). The second row is the number of individuals measured when including all age measurements, with the total number of observations (including repetitions on individuals) in brackets. The third row is the mean number of repetitions per individual, with the range for all individuals in brackets. The total number of individuals in row 2 is larger than the number of individuals measured at first age in row 1 because some individuals were not measured at first age but their cohort year was known and thus they could be assigned to a cohort cluster and added to the analyses starting from Step 2.

${ }^{\varnothing}$ In some populations, the first body size measurements were collected after the first summer of life, which we referred to as age 0 , whereas in other populations the first measurements were available after the first year of life only, which we referred to as age 1 . The exact timing when measurements were taken each year is specified in the column "Body size measure".

${ }^{\Delta}$ In elephants, age at which cohort was measured is over a longer period because of the longer inter-birth interval (IBI) compared with the other species (see Methods).
}

This article is protected by copyright. All rights reserved 
Age $=$ the age when the body size of the cohort was measured (in years).

$\mathrm{N}=$ the number of cohorts available.

$K=$ the number of cohort clusters selected by the mixture models.

$\mathrm{R}^{2}=$ the coefficient of determination for the mixture model with $K$ clusters, computed as the complement of the within cluster/total variance ratio to 1 (i.e. $1-$ (within-cluster variance/total variance)), where the total variance is the sum of the between- and within-cluster variance (equation 6.5 p. 170 in Frühwirth-

Schnatter 2006).

$\mathrm{GT}=$ the generation time, in years, computed as $\mathrm{T}_{\mathrm{b}}$ according to Lebreton (2005).

1: Lee et al. (2013), 2: Festa-Bianchet and Côté (2008), 3: Hamel et al. (2010), 4: Hamel et al. (2012), 5: Green and Rothstein (1991), 6: Festa-Bianchet et al. (2000), 7: Stien et al. (2002), 8: Bårdsen and Tveraa (2012), 9: Gaillard et al. (2003a), 10: Gaillard et al. (2003b), 11: Pettorelli et al. (2002), 12: Plard et al. (2014), 13: Clutton-Brock and Pemberton (2004), 14: Garel et al. (2005), 15: Garel et al. (2007).

Table 2. Overview of the research questions about cohort effects in large herbivores, the methods applied to answer these questions, and the variables used at each step of this study.

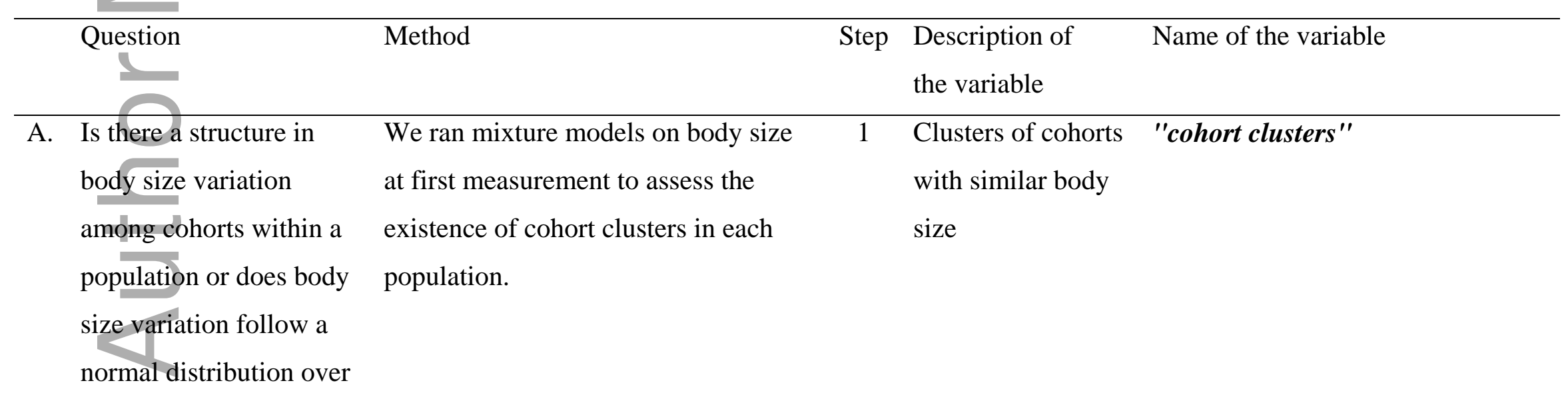

This article is protected by copyright. All rights reserved 
all cohorts?

B. Do cohort clusters show different growth trajectories?
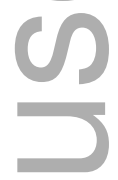

C. How does the magnitude of cohort variation in body size change with age? Does this differ among species and between sexes?

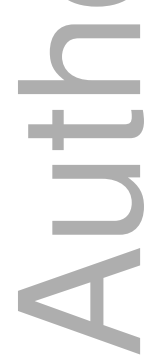

We fitted linear mixed models and tested for an interaction between age and cluster. From these growth trajectories, we then extracted expected body size at each age for each cohort cluster.

From the "body size" measures obtained for each cohort cluster (Step 2 ), we scaled the difference among cohort clusters as the relative difference from the mean population value at each age.

From the "relative difference" measures (Step 3), we calculated the range in relative differences among all
2 Growth trajectory of each cohort cluster, i.e. mean body size at each age (Fig. S1)

$3 \quad$ Standardized growth trajectory of each cohort cluster, i.e. relative difference in body size at each age (Fig. 3)

$4 \quad$ Magnitude of cohort variation in size at each age "body size"

"relative difference"

"range of relative differences" 
D. Does the change with age in cohort body size variation result from cumulative or compensatory effects? Does this differ among species and between sexes?

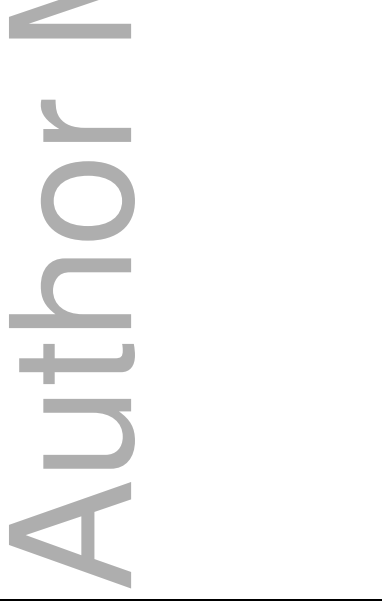

cohort clusters at each age. Then, we

assessed the influence of age, sex and generation time on this variable.

(Fig. 4)

From the "relative difference"

measures (Step 3), we calculated the

difference in relative differences

between each pair of cohort clusters

for a given sex in a given population.

From the "paired relative difference" measures (Step 5), we computed the relative change in paired relative differences between cohort clusters from age $x$ to age $x+1$. Then, we assessed the influence of age, sex and generation time on this variable.
5 Magnitude of "paired relative differences" cohort variation in size at each age computed for each pair of cohort clusters

(Fig. 6)

6 Relative change "relative change from age to age" with age in cohort variation between each pair of cohort cluster

(Fig. 7) 


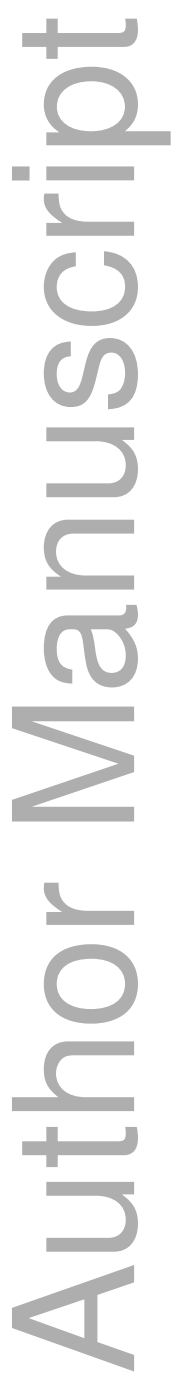

This article is protected by copyright. All rights reserved 
Table 3. ANOVA table for the sequential ${ }^{\Delta}$ effects of age, sex, generation time, and their interactions on a) the range of relative differences in size among cohort clusters, b) the relative change from age to age in cohort variation in size (i.e. relative change in paired relative differences, see Table 2), and c) the relative change from age to age in cohort variation in size excluding the influence of viability selection, thereby representing differences in growth only.

\begin{tabular}{lllrrrr}
\hline Sariables & MSS & Num DF & Den DF* & F value & P value \\
\hline a) Range of relative difference (Step 4) & & & & & & \\
Age & 9.93 & 3.31 & 3 & 192 & 59.0 & $<0.001$ \\
Sex & 2.39 & 2.39 & 1 & 192 & 42.5 & $<0.001$ \\
GT & 2.70 & 2.70 & 1 & 192 & 48.0 & $<0.001$ \\
Age* Sex & 0.61 & 0.20 & 3 & 192 & 3.6 & 0.01 \\
Age* GT & 0.15 & 0.05 & 3 & 192 & 0.9 & 0.4 \\
b) Relative change from age to age (Step 6) & & & & & & $<.9$ \\
Age & $1.18^{-4}$ & $0.39^{-4}$ & 3 & 400.8 & 22.3 & $<0.001$ \\
Sex & $0.10^{-4}$ & $0.10^{-4}$ & 1 & 396.3 & 5.9 & 0.02 \\
GT & $0.08^{-4}$ & $0.08^{-4}$ & 1 & 41.4 & 4.7 & 0.04 \\
Age * Sex & $0.33^{-4}$ & $0.11^{-4}$ & 3 & 400.5 & 6.2 & $<0.001$ \\
Age* GT & $0.32^{-4}$ & $0.11^{-4}$ & 3 & 400.5 & 6.0 & $<0.001$
\end{tabular}

This article is protected by copyright. All rights reserved 
c) Relative change from age to age - differences in growth only

$\begin{array}{llllrrr}\text { Age } & 0.49^{-4} & 0.16^{-4} & 3 & 401.7 & 12.1 & <0.001 \\ \text { Sex } & 0.13^{-4} & 0.13^{-4} & 1 & 397.9 & 9.5 & 0.002 \\ \text { GT } & 0.01^{-4} & 0.01^{-4} & 1 & 37.3 & 1.1 & 0.3 \\ \text { Age * Sex } & 0.30^{-4} & 0.10^{-4} & 3 & 401.2 & 7.2 & <0.001 \\ \text { Age *GT } & 0.11^{-4} & 0.04^{-4} & 3 & 401.7 & 2.7 & 0.04\end{array}$

${ }^{\overline{ }}$ Variables were assessed sequentially in the ANOVA in the order they are presented. In such cases, when interactions are statistically significant, the strength of the main effects needs to be assessed considering the influence of interactions by comparing the estimates for the interactions as well as the sum of squares of the main effects. In "a" for instance, the interaction of age with sex is statistically significant, but it is clear from both the estimates of the interaction (Fig. 5) and the high sum of squares for age compared with the interaction that the decrease with age corresponds to a strong main effect irrespective of the differences between sexes.

* For the linear mixed model (i.e. in b and c), the ANOVA table was computed with the Satterthwaite approximation for the degrees of freedom.

$\mathrm{SS}=$ Sum of squares.

MSS = Mean sum of squares.

Num DF $=$ degrees of freedom at the numerator.

Den $\mathrm{DF}=$ degrees of freedom at the denominator.

$\mathrm{GT}=$ generation time, in years, computed as $\mathrm{T}_{\mathrm{b}}$ according to Lebreton (2005). 
Table 4. Likelihood ratio tests evaluating whether the LMM on body size trajectories including age at last measurement as a covariate received more support than the same LMM excluding this covariate. We present the P-value of the likelihood test for each cohort cluster for a given sex and population, with the number of individuals included in each cluster ( $\mathrm{Nb}$ ID). In bold-italic, we highlight support or a tendency to support the model including age at last measurement, and thereby the presence of viability selection.

\begin{tabular}{|c|c|c|c|c|c|}
\hline \multirow{2}{*}{ 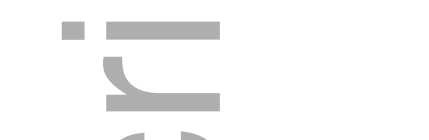 } & & \multicolumn{2}{|c|}{ Males } & \multicolumn{2}{|c|}{ Females } \\
\hline & & $\mathrm{P}$ value & $\mathrm{Nb}$ ID & $\mathrm{P}$ value & $\mathrm{Nb}$ ID \\
\hline African elephants & Gr 1 & 0.3 & 249 & 0.07 & 280 \\
\hline Mountain goats & Gr 1 & 0.6 & 153 & 0.4 & 138 \\
\hline & Gr 2 & 0.7 & 11 & 0.9 & 21 \\
\hline Plain bison (Konza) & Gr 1 & $<0.001$ & 105 & $<0.001$ & 83 \\
\hline & Gr 2 & $<0.001$ & 184 & $<0.001$ & 172 \\
\hline & Gr 3 & $<0.001$ & 274 & $<0.001$ & 300 \\
\hline Plain bison (Wind Cave) & Gr 1 & $<0.001$ & 236 & 0.1 & 248 \\
\hline & Gr 2 & 0.6 & 238 & 1 & 203 \\
\hline & Gr 3 & 0.04 & 149 & 0.5 & 165 \\
\hline & Gr 4 & 0.01 & 385 & 0.8 & 317 \\
\hline Bighorn sheep & Gr 1 & 0.2 & 60 & 0.2 & 88 \\
\hline & Gr 2 & 0.3 & 83 & 0.01 & 82 \\
\hline & Gr 3 & 0.8 & 136 & $<0.001$ & 134 \\
\hline Svalbard reindeer & Gr 1 & - & - & 0.3 & 173 \\
\hline & Gr 2 & - & - & 0.2 & 273 \\
\hline & Gr 3 & - & - & 0.6 & 172 \\
\hline Reindeer (Ravdol) & Gr 1 & - & - & 0.9 & 218 \\
\hline
\end{tabular}




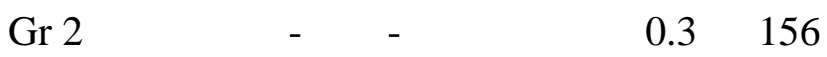

\begin{tabular}{|c|c|c|c|c|c|}
\hline Roe deer (Chizé) & Gr 1 & $<0.001$ & 183 & 0.002 & 173 \\
\hline & Gr 2 & 0.02 & 175 & $<0.001$ & 168 \\
\hline & Gr 3 & $<0.001$ & 251 & 0.004 & 203 \\
\hline Roe deer (Trois Fontaines) & Gr 1 & 0.8 & 66 & $<0.001$ & 84 \\
\hline & Gr 2 & 0.8 & 298 & 0.01 & 280 \\
\hline & Gr 3 & $<0.001$ & 101 & 1 & 86 \\
\hline Soay sh & Gr 1 & $<0.001$ & 401 & $<0.001$ & 475 \\
\hline & Gr 2 & 0.3 & 167 & 0.002 & 203 \\
\hline & Gr 3 & $<0.001$ & 185 & 0.2 & 243 \\
\hline & Gr 4 & $<0.001$ & 611 & $<0.001$ & 644 \\
\hline Mouflon & Gr 1 & 0.8 & 177 & 0.02 & 139 \\
\hline 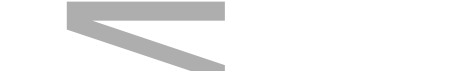 & Gr 2 & 0.7 & 83 & 0.01 & 81 \\
\hline & Gr 3 & 1 & 383 & 0.9 & 303 \\
\hline
\end{tabular}

Figure 1. Conceptualization of the potential influence of environmental conditions on the between-individual variance in a life-history trait. The black curves represent individual responses and the red dotted curve is the overall population response. A: Variance among individuals is initially low and remains constant with age. B: Variance is initially high and remains constant with age. $\mathrm{C}$ : The trait of individuals with a low initial value (a bad start in life) increases faster than that of individuals with higher initial trait values, which indicates a compensatory effect resulting in smaller differences among individuals at older ages. D: The trait of individuals with a low initial trait value increases less than that of individuals with higher initial trait values: individual differences for the trait accumulate over ages, resulting in a cumulative effect. E: Individuals with a low initial value die earlier than individuals with a high initial value, viability selection leads to a 
decrease in the initial differences through selective disappearance. For simplicity, trajectories are assumed to be linear, but the patterns are similar for non-linear trajectories.

Figure 2. Summary of the 6 steps to analyze cohort variation and its change throughout lifetime, illustrating two contrasting examples: bighorn sheep in the top two rows and Soay sheep in the bottom two rows. In Step 1, the number of clusters is selected based on a mixture model including body size measures from both sexes at the first age of measurement (see Table 1): only one measurement is included per individual. In this step, different selection criteria provided different plausible numbers of clusters, $K$, which are illustrated in the different panels, and the best alternative (in color) was determined as the highest alternative without cluster overlap in the $95 \%$ confidence intervals (CI). In Step 2 , growth trajectory for each cluster presents the mean prediction and $95 \%$ CI extracted from a model using all body size measurements. Step 3 illustrates the standardized growth trajectories of cohort clusters, which is the difference of each trajectory obtained in Step 2 in relation to the predicted mean trajectory for a given population and sex. The dots are the mean relative differences and the bars their 95\% CI. Grey bars indicate ages when not all clusters were measured. The same clusters are represented with the same colors in Steps 1, 2 and 3. In Step 4, the magnitude of cohort variation in size was calculated using the range of relative differences among all cohort clusters as a metric. The dots are the mean relative differences and the bars are their $95 \% \mathrm{CI}$, with grey symbols for ages when at least one cohort cluster was missing because no individual of that age or older was sampled. In bighorn sheep for example, the magnitude of cohort variation in size remained high at all ages in males, but decreased rapidly to near 0 in females. In Step 5, the relative difference between each pair of cohort clusters was calculated. A given color illustrates a given pair, with dotted lines from ages when at least one cohort cluster was missing. In Step 6, the relative change from age to age in cohort variation in body size was computed from the values obtained at Step 5, i.e. the paired relative differences. A positive value represents increased size variation between a pair of cohort clusters, indicating a cumulative effect, whereas a negative value represents decreased size variation between a pair of cohort clusters, and hence a compensatory 
effect. A value of 0 indicates that variation in size between a pair of cohort clusters remains similar with increasing age. The colors in Step 6 match the trajectories representing the different pairs of cohort clusters in Step 5. For example, compensation was stronger in Soay sheep than in bighorn sheep, particularly in males, and differences remained relatively stable with age in male bighorn sheep compared with other sexspecies cases.

Figure 3. The difference in the trajectory of each cohort cluster relative to the predicted mean (specific to each population and sex), illustrating the standardized growth of the different cohort clusters (Step 3) for each population (ordered from a long (left) to a short (right) generation time, corresponding to the "slow-fast" continuum of life histories) and sex (females: top, males: bottom). The dots are the mean relative differences and the bars represent the $95 \%$ confidence intervals. Grey bars correspond to ages from which at least one cohort cluster was missing.

Figure 4. The magnitude of cohort variation in size at each age (Step 4), i.e. the range of relative differences among all cohort clusters (computed from the standardized growth, Step 3; Fig. 3), for each population (ordered from a long (left) to a short (right) generation time, corresponding to the "slow-fast" continuum of life histories) and sex (females: top, males: bottom). The dots are the means and the bars represent the $95 \%$ confidence intervals. Grey symbols correspond to ages when data were missing for at least one cohort cluster.

Figure 5. Change with age in the range of relative differences in size (Step 4) in relation to sex (males: dotted lines, light grey zones, blue dots; females: solid lines, dark grey zones, pink dots) and generation time (GT). The lines are the mean predictions and the zones are the $95 \%$ confidence intervals. The dots show the partial residuals, which account for the effects of other variables in the model. Age was standardized to account for differences in the length of the time series among populations and sexes. 
Figure 6. The paired relative differences in size between cohort clusters (Step 5) in relation to age (computed from the standardized growth trajectories, Step 3; Fig. 3), for each population (ordered from a long (left) to a short (right) generation time, corresponding to the "slow-fast" continuum of life histories) and sex (females: top, males: bottom). Each color corresponds to a specific pair, with dotted lines at ages when data for some cohort clusters were not available.

Figure 7 . The relative change from age to age in cohort variation in size between each pair of cohort clusters (Step 6) in relation to age (computed from the values compiled at Step 5; Fig. 6), for each population (ordered from a long (left) to a short (right) generation time, corresponding to the "slow-fast" continuum of life histories) and sex (females: top, males: bottom). A positive value indicates an increase in the difference in size between a pair of cohort clusters, and thereby a cumulative effect, whereas a negative value indicates a decrease in the difference in size between a pair of cohort clusters, and hence a compensatory effect. A value of 0 indicates that the difference in size between a pair of cohort clusters remains constant with age. The colors match the trajectories representing the different pairs of cohort clusters in Fig. 6.

Figure 8. Variation in the relative change from age to age (Step 6) in relation to sex (males: dotted lines, light grey zones, blue dots; females: solid lines, dark grey zones, pink dots) and generation time (GT). The lines are the mean predictions and the zones are the $95 \%$ confidence intervals. The dots show the partial residuals, which account for the effects of other variables in the model. The red line at 0 separates compensatory effects below and cumulative effects above. Age was standardized to account for differences in the length of the time series among populations and sexes.

Figure 9. Effect of viability selection on growth trajectories in three cohort clusters of male roe deer at Chizé. Each color represents a different cohort cluster. A: Trajectories with the same colors represent mean growth predictions for individuals of the same cohort cluster but with different ages at last measurement, with the age at last measurement illustrated by the dot. B: The mean growth trajectory for each cohort cluster 
adjusted for age at last measurement (dotted lines) compared with the unadjusted growth trajectories (i.e. Step 2; continuous lines).

Figure 10. Variation in the relative change from age to age only due to differences in growth, in relation to sex (males: black dotted lines, light grey zones; females: black solid lines, dark grey zones) and generation time (GT). The black lines are the mean predictions and the zones are the $95 \%$ confidence intervals (for clarity, the partial residuals are not shown, see Fig. 8). The red line at 0 separates compensatory effects below and cumulative effects above. The blue (males) and pink (females) lines represent the difference between the mean predictions of the relative change from age to age due to both viability selection and growth (black lines in Fig. 8) minus those only due to differences in growth (the black lines in this figure), thereby highlighting the influence of viability selection on the relative change from age to age for each sex. Age was standardized to account for differences in the length of the time series among populations and sexes.
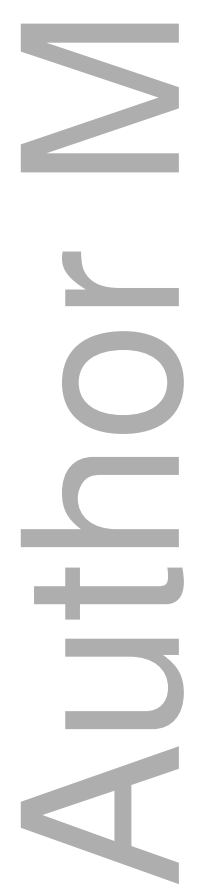
Low initial variance,

High initial variaece)_1232_f1.pptx

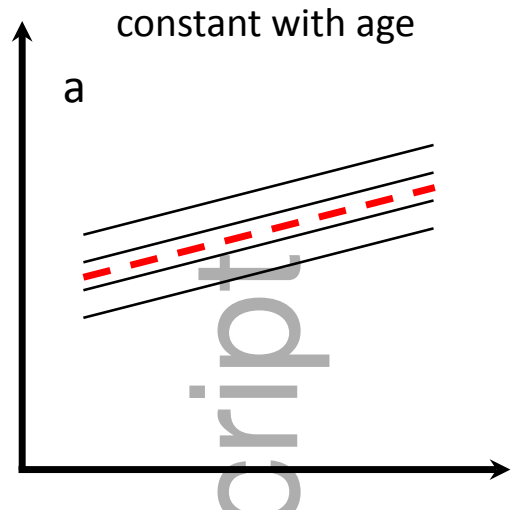

constant with age

$\mathrm{b}$
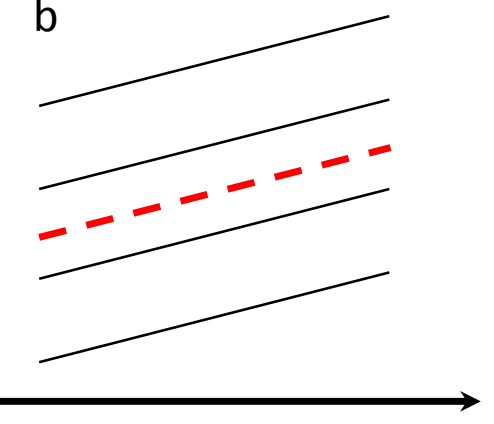

Variance declines with age:

Variance increases with age:

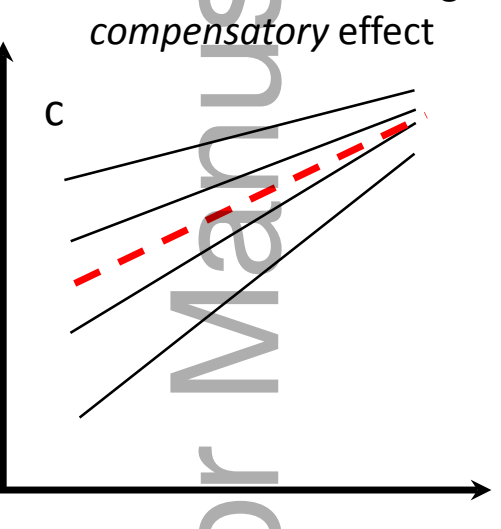
cumulative effect

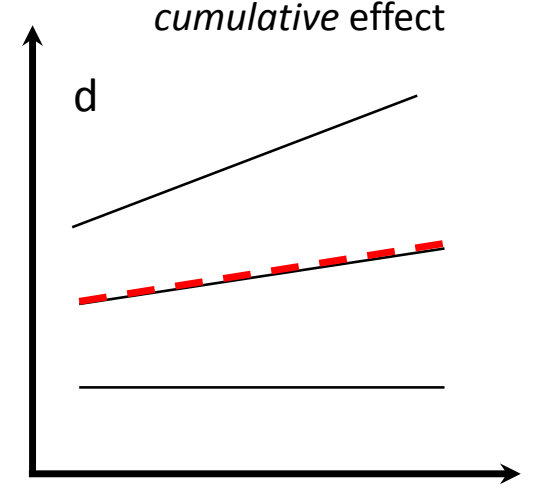

Variance declines with age: disappearance effect

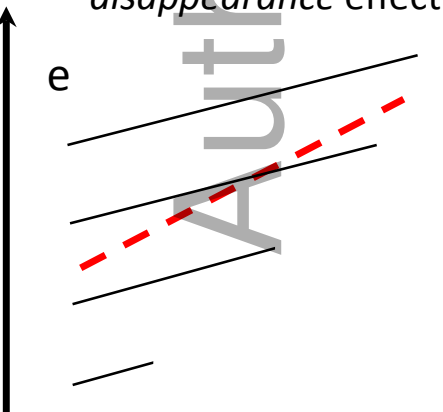

This article is protected by copyright. All rights reserved

\section{Age}


FEMALES
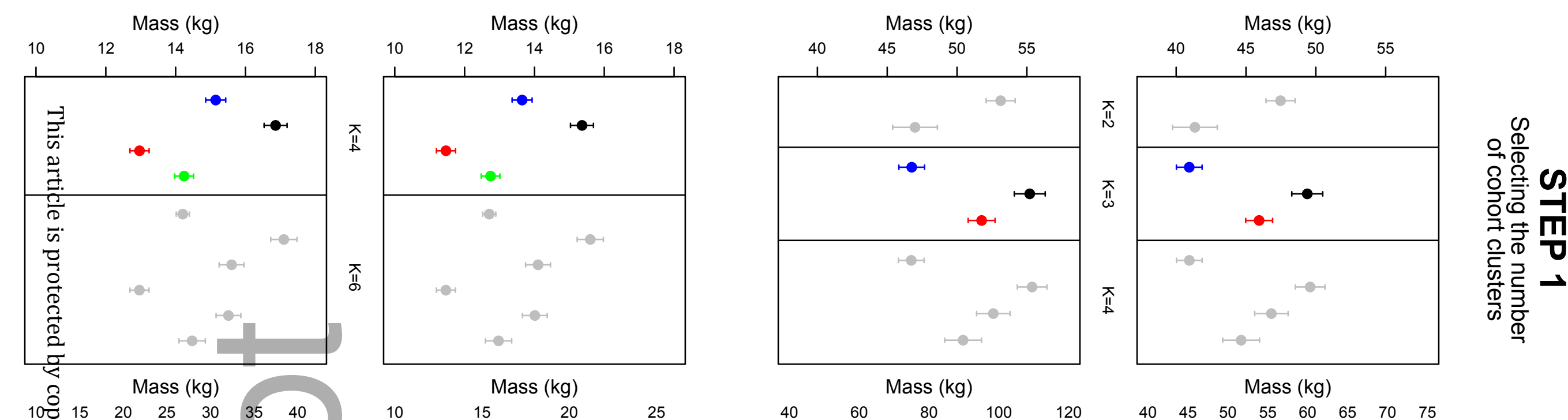

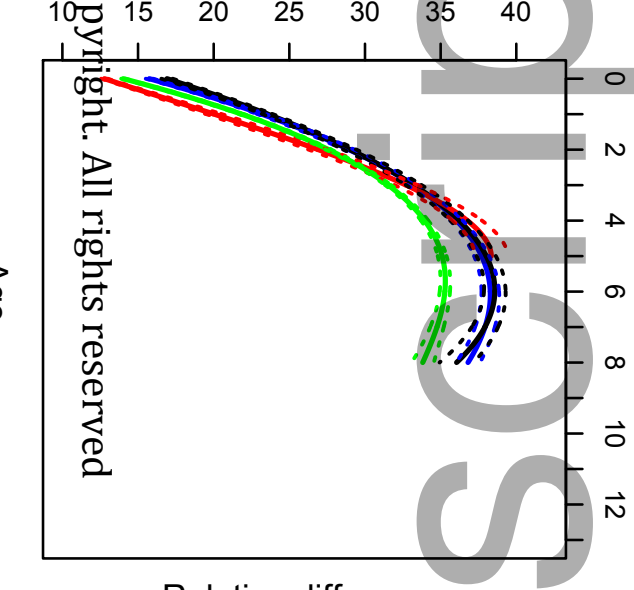

Relative difference
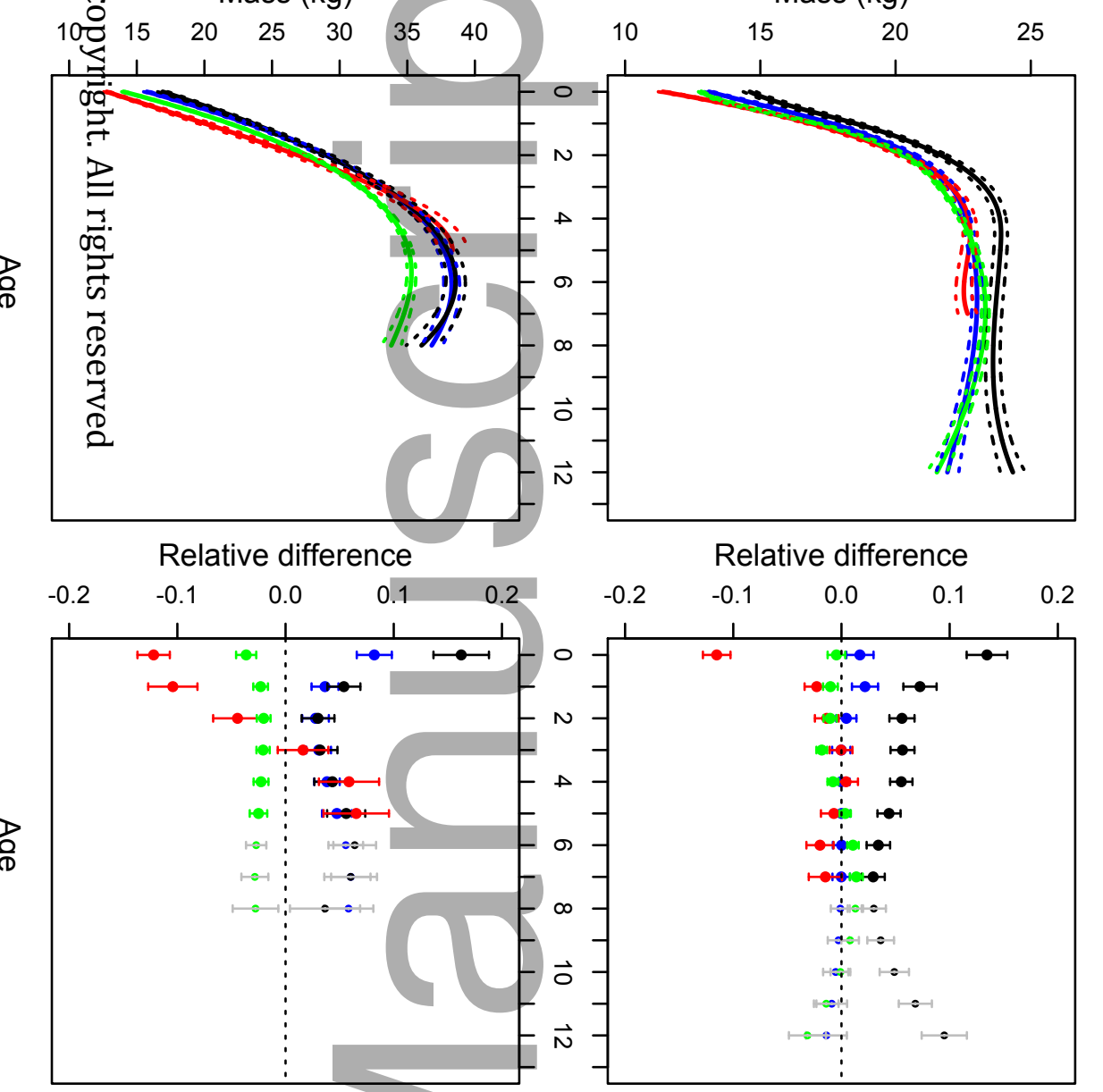

Range of relative differences
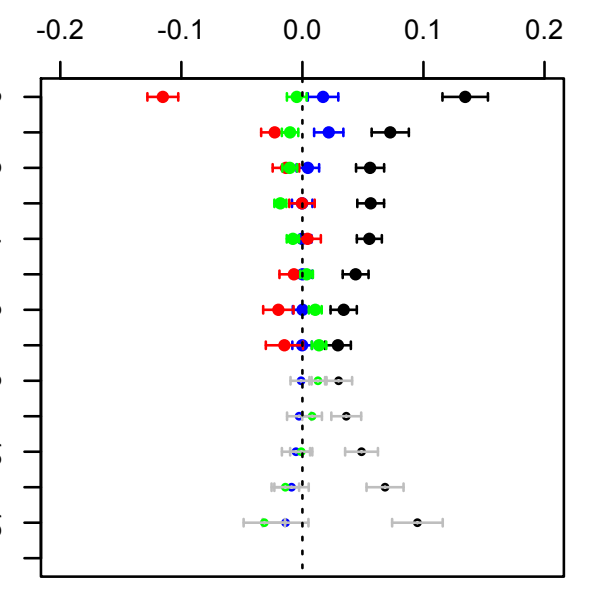

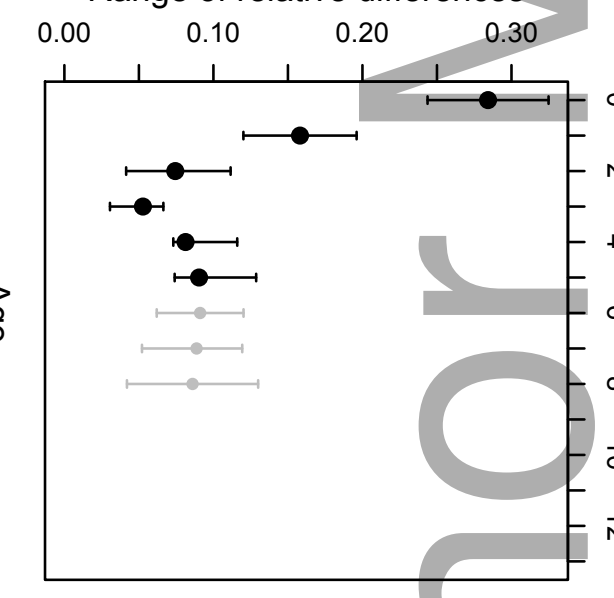

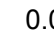$$
\text { (n) }
$$

Paired relative differences $\begin{array}{lllllll}0.00 & 0.05 & 0.10 & 0.15 & 0.20 & 0.25 & 0.30\end{array}$
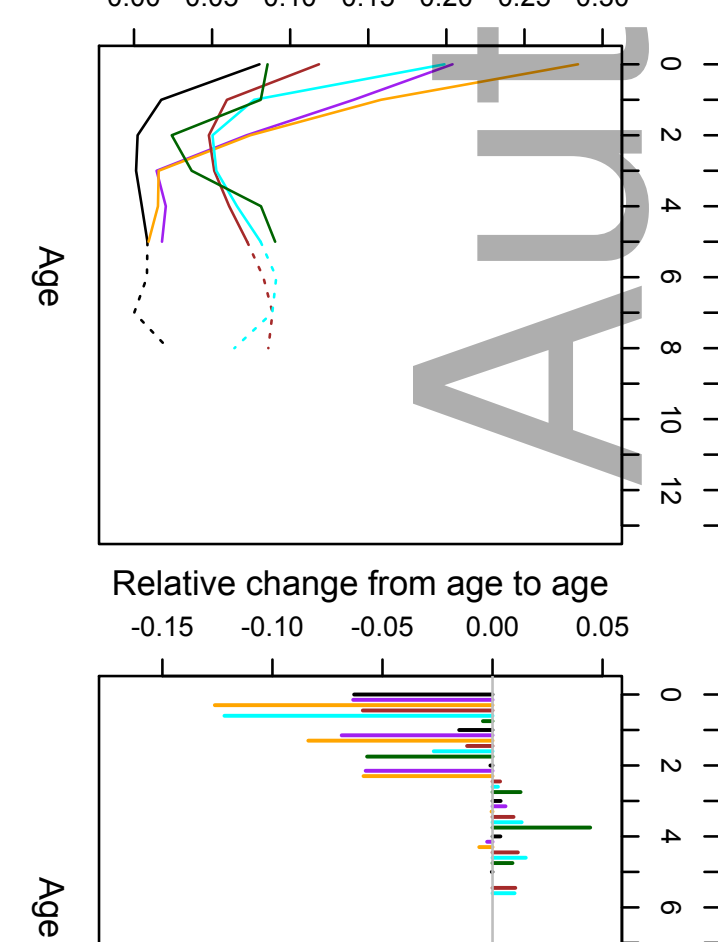

Relative change from age to age $\begin{array}{lllll}-0.15 & -0.10 & -0.05 & 0.00 & 0.05\end{array}$
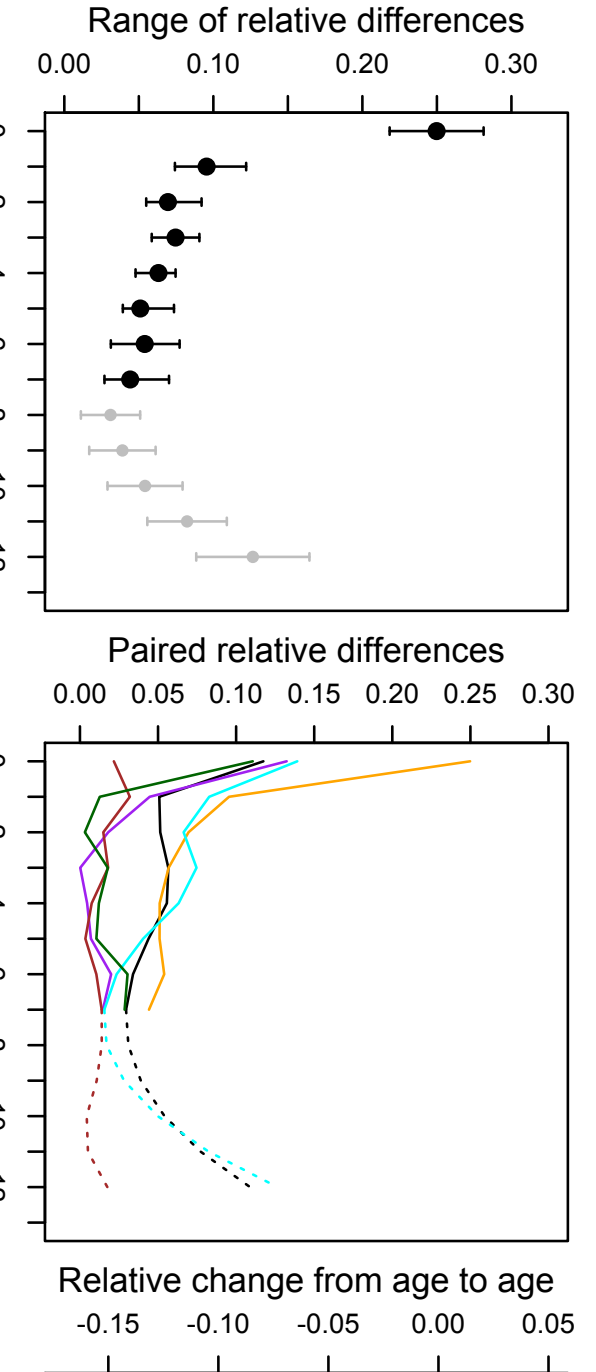

Paired relative differences $\begin{array}{lllllll}0.00 & 0.05 & 0.10 & 0.15 & 0.20 & 0.25 & 0.30\end{array}$

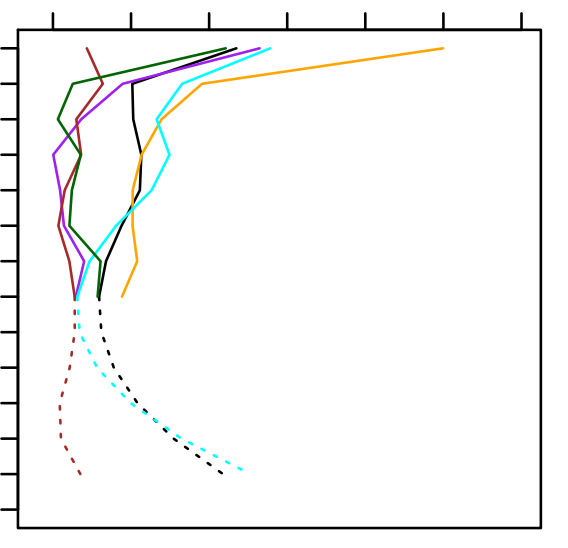

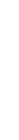

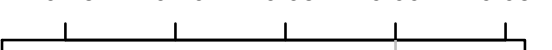

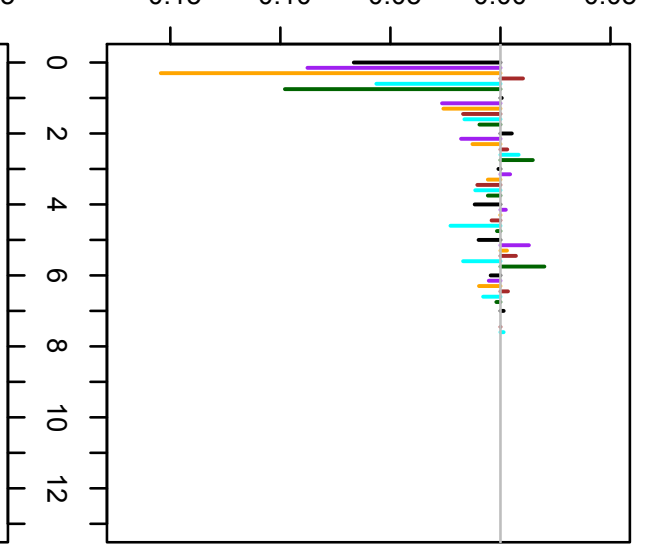
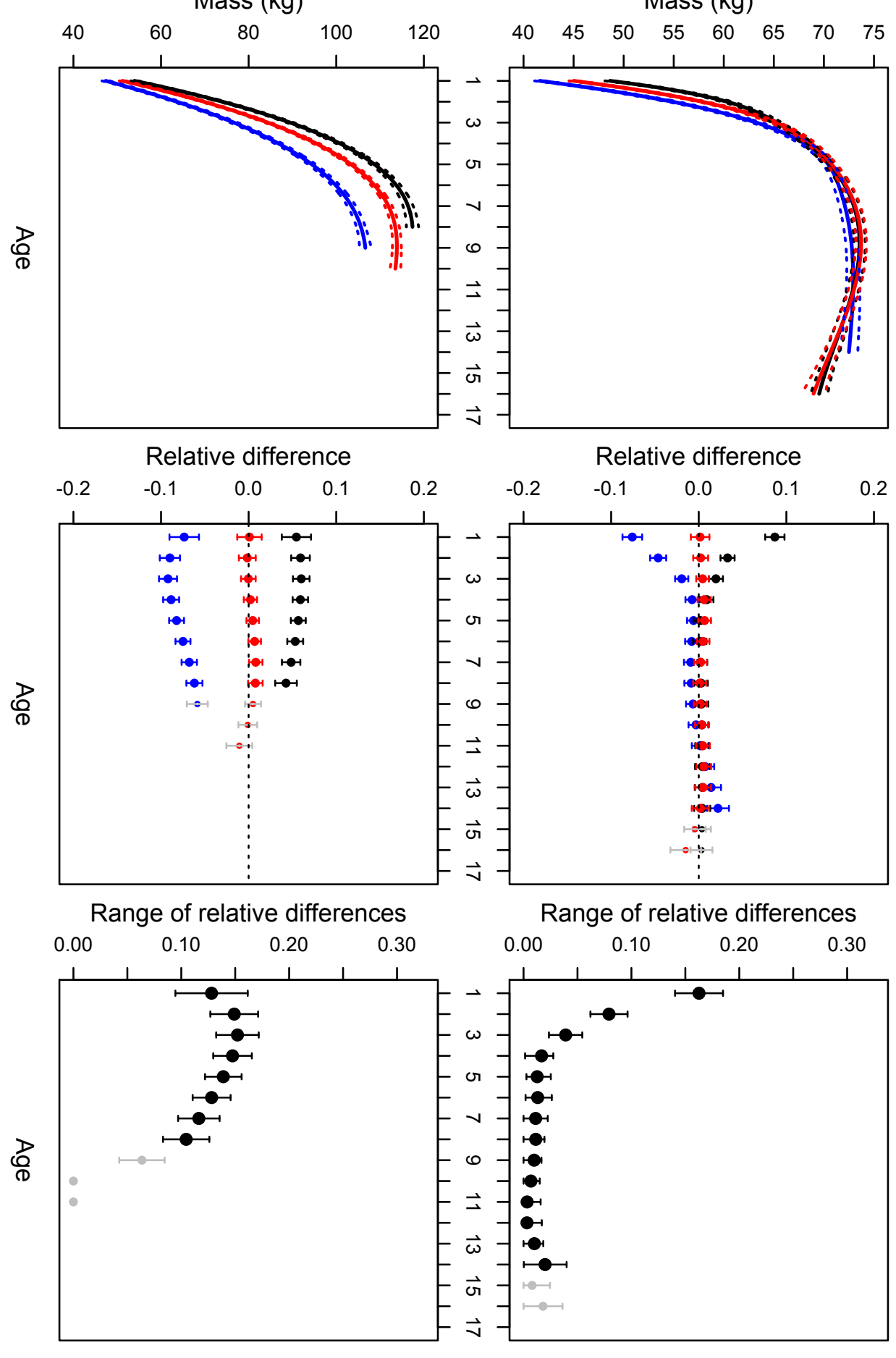

Paired relative differences
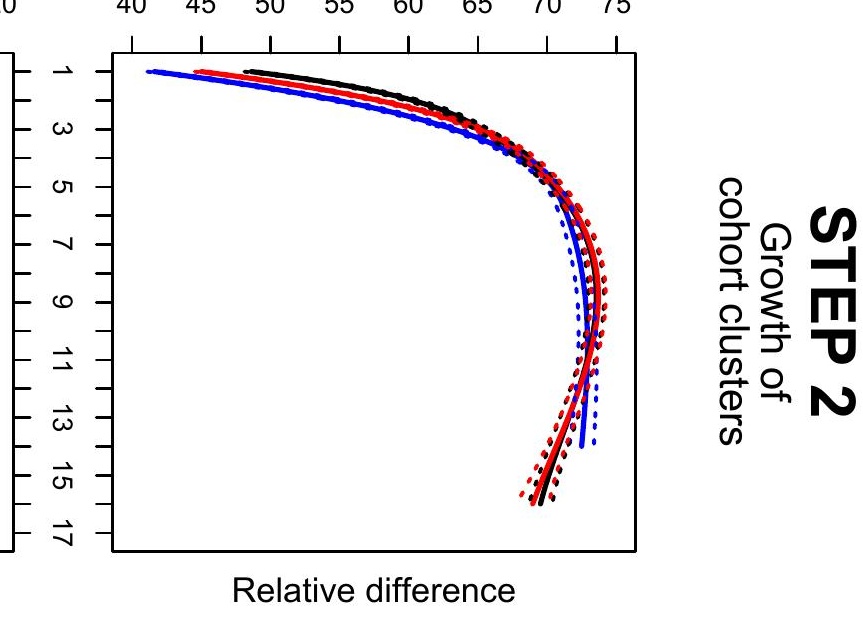
$\begin{array}{lllllll}0.00 & 0.05 & 0.10 & 0.15 & 0.20 & 0.25 & 0.30\end{array}$
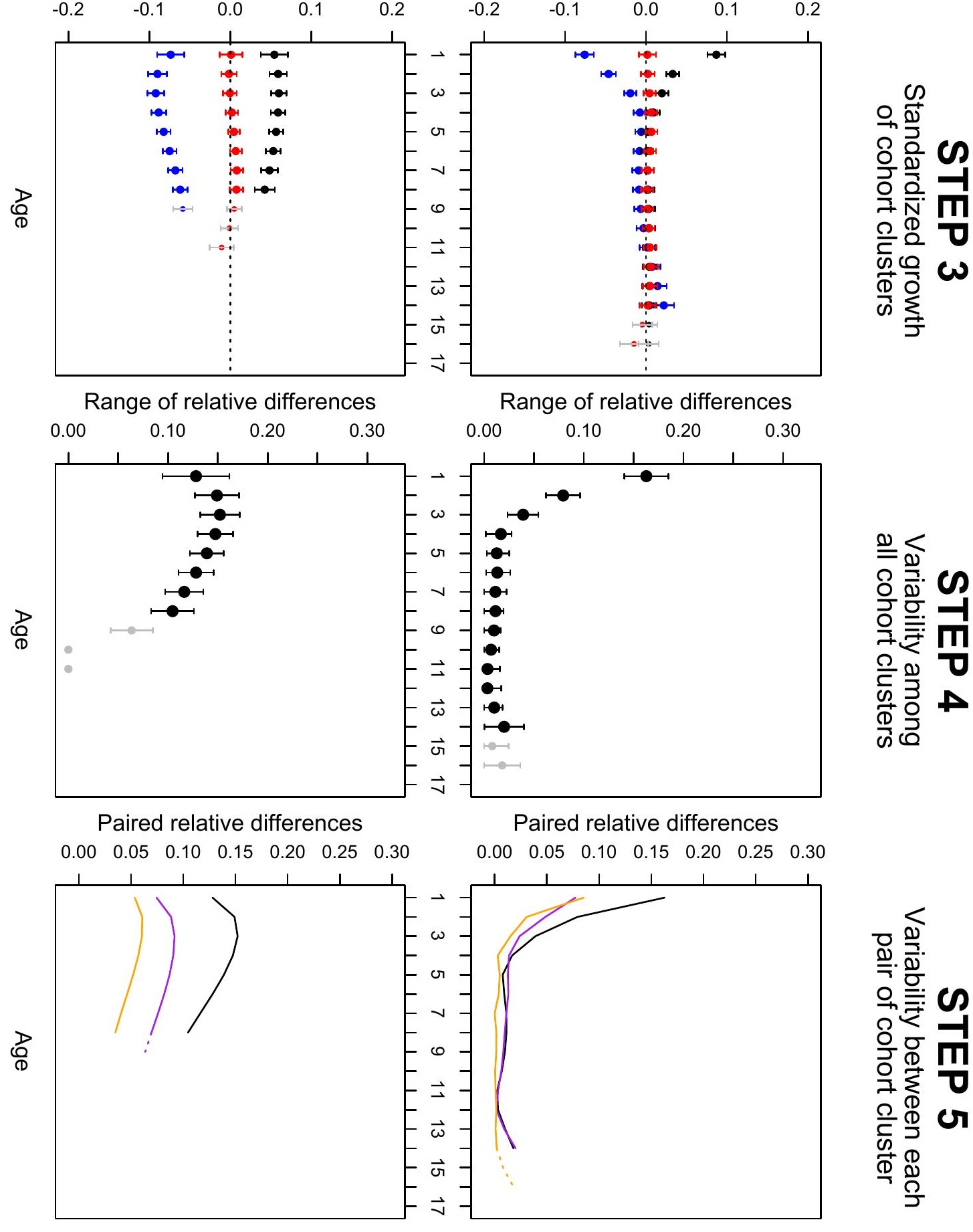

Relative change from age to age
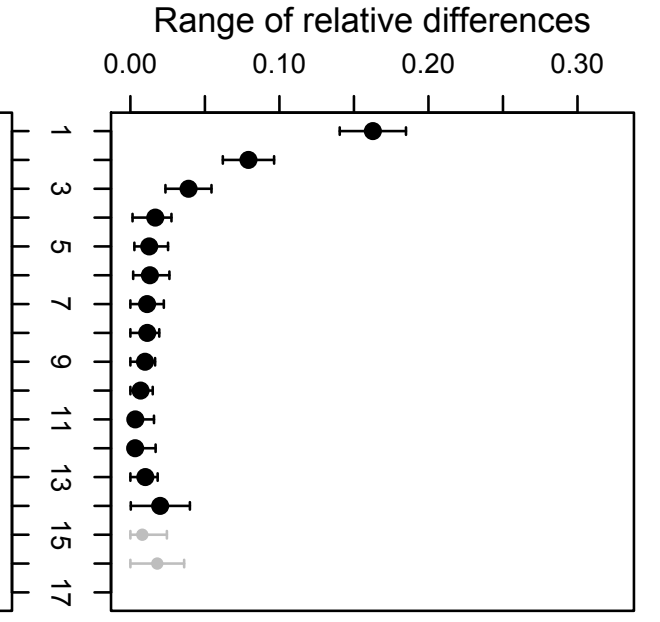

Paired relative differences $\begin{array}{lllllll}0.00 & 0.05 & 0.10 & 0.15 & 0.20 & 0.25 & 0.30\end{array}$

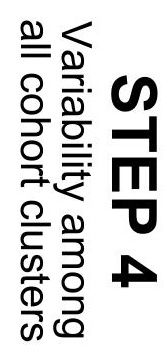

$\begin{array}{lllll}-0.15 & -0.10 & -0.05 & 0.00 & 0.05\end{array}$

Relative change from age to age

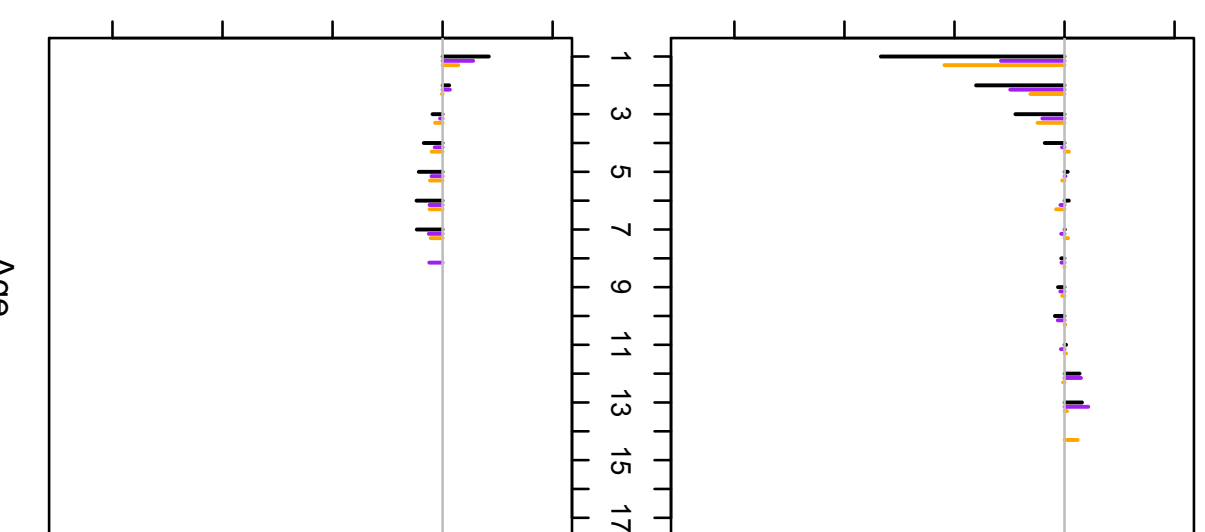

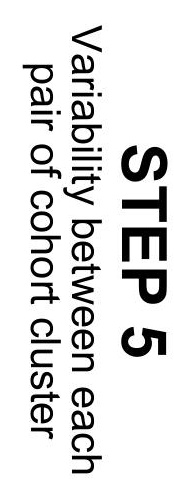

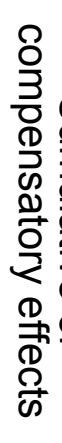




\section{University Library}

\section{- M I N E R VA}

\section{A gateway to Melbourne's research publications}

Minerva Access is the Institutional Repository of The University of Melbourne

\section{Author/s:}

Hamel, S;Gaillard, J-M;Yoccoz, NG;Albon, S;Cote, SD;Craine, JM;Festa-Bianchet, M;Garel, M;Lee, P;Moss, C;Nussey, DH;Pelletier, F;Stien, A;Tveraa, T

Title:

Cohort variation in individual body mass dissipates with age in large herbivores

Date:

2016-11-01

\section{Citation:}

Hamel, S., Gaillard, J. -M., Yoccoz, N. G., Albon, S., Cote, S. D., Craine, J. M., FestaBianchet, M., Garel, M., Lee, P., Moss, C., Nussey, D. H., Pelletier, F., Stien, A. \& Tveraa, T. (2016). Cohort variation in individual body mass dissipates with age in large herbivores. ECOLOGICAL MONOGRAPHS, 86 (4), pp.517-543. https://doi.org/10.1002/ecm.1232.

Persistent Link:

http://hdl.handle.net/11343/292102 